\title{
Market Access, Investment, and Heterogeneous Firms
}

\author{
Alan C. Spearot * \\ University of California - Santa Cruz
}

April 29, 2012

\begin{abstract}
This paper presents a model of international trade in which heterogeneous firms can expand through capital acquisitions. I show that demand elasticities are a crucial element in predicting which firms invest, in what location, and for what reason. High productivity firms, who tend to sell goods at a low elasticity, invest for market access (tariff jumping). Middle productivity firms, who tend to sell at a higher elasticity, invest for productivity improvement. The relative value of trade costs dictates which incentive is larger. In equilibrium, trade liberalization can reduce aggregate productivity by reducing an important source of investment demand: foreign firms.
\end{abstract}

JEL Classifications: F12, F23, G34, L23

Keywords: Firm Heterogeneity, Foreign Direct Investment, Multinational Enterprise, Mergers and Acquisitions, Trade Liberalization, Aggregate Productivity, Variable Elasticities

\footnotetext{
*Email: acspearot@gmail.com. Address: Economics Department, 1156 High Street, Santa Cruz, CA, 95064. Tel.: +1 831419 2813. I thank Charles Horioka and three anonymous referees for helpful comments. This paper has also benefited from useful comments by Tor-Erik Bakke, Menzie Chinn, Federico Díez, Charles Engel, John Kennan, Mina Kim, Phillip McCalman, Marc Muendler, and Robert Staiger, and presentations at UC-Davis, UC-Santa Cruz, Boston College, Syracuse, Washington State, Wisconsin, SCCIE 2007 and EIIT 2006. All remaining errors are my own.
} 


\section{Introduction}

Without question, foreign direct investment (FDI) is one of the fastest growing aspects of globalization. While FDI can take many forms, one in particular, cross-border mergers and acquisitions (M\&As), has exhibited explosive growth over the last two decades. ${ }^{1}$ Indeed, the rapid growth of cross-border M\&As has not gone unnoticed by policymakers and analysts. ${ }^{2}$ However, a fact often masked by the rapid and public growth of cross-border M\&As is that domestic acquisitions are far more common. ${ }^{3}$ This begs the following question: how do firms balance incentives for domestic and foreign acquisitions?

Despite the well-known "proximity" benefits of foreign investment, many incentives for crossborder acquisitions derive from factors that also motivate domestic acquisitions. For example, market power, risk sharing, brand expansion, and cost reduction are all incentives that may motivate mergers of both the domestic and foreign variety. As all of these incentives may influence the market clearing price for assets on a merger market, cross-border M\&As to obtain foreign market access must not be examined in a vacuum. Further, as traditional trade policy parameters such as tariffs can influence the relative prominence of foreign acquisitions relative to domestic, the incentives to levy such tariffs may not solely be a function of market access, but may also extend to how tariffs affect the market for corporate control.

In this paper, I examine the interaction between acquisitions for foreign market access and acquisitions for cost reduction. In doing so, I derive two novel contributions related to domestic and foreign acquisition behavior. First, I show that using a common variable-elasticity (linear) demand system, firms that benefit from acquisitions for market access are not the same firms that benefit from acquisitions for cost reduction. Hence, the relative size of trade costs determines the qualitative sorting of firms into acquisition choices. Second, I identify a role of foreign acquisitions in tempering, and in some cases reversing, the beneficial effects of trade liberalization. Hence, contrary to conventional wisdom, positive trade barriers may be optimal to not shift profits from foreign to home producers, but instead to induce a larger reallocation from the inefficient to the efficient.

The key to the model is how acquisitions may reduce cost, and when they do, how these cost reductions result in higher profits. Generally, I view acquisitions as an opportunity to exploit synergies in variable costs. In particular, if production by a merged firm is less than the combined production of the old firms - a common prediction in almost all acquisition models - the acquisition

\footnotetext{
${ }^{1}$ In absolute terms, according to the OECD (2001), the value of cross-border M\&As increased five-fold over the period 1990-1999. Relatively, the growth of cross-border M\&As has also been substantial, where the share of North American firms that acquired cross-border rather than domestically increased 133\% between 1985 and 2004 (author's calculation using the Thomson SDC Platinum database.)

${ }^{2}$ Put concisely by UNCTAD (2000), "Indeed, perhaps to a greater extent than many other aspects of globalization, cross-border M\&As and the expanding global market for firm ownership and control in which they occur - raise questions about the balance of their benefits and costs for host countries".

${ }^{3}$ For example, using the Thomson SDC Platinum database, the yearly (count) share of foreign acquisitions within worldwide mergers over the period 1980-2006 is uniformly less than one-third.
} 
allows the acquiring firm to reallocate production amongst the best assets of both firms. This might include reducing the amount of overtime shifts, firing the least productive workers, specialization in tasks across firms, retiring the oldest machinery, or reducing output at inefficient plants and increasing output at more efficient plants. The question then becomes, how do these variable cost improvements result in higher profits? Further, how are these incentives balanced with opportunities for additional market access by acquiring assets in other markets?

Abstracting from issues of market access, the demand function governs how cost reductions map into higher profits. In many models of firm heterogeneity and investment, and often as a matter of analytical convenience, the constant-elasticity (CES) assumption is used to characterize demand. Under CES, high productivity firms operate on the relatively flat portion of the demand curve. Thus, even a small reduction in costs has the potential to yield huge gains in profits. However, this result is empirically questionable in light of an abundance of evidence suggesting that elasticities are variable. ${ }^{4}$ In particular, when the absolute elasticity of demand is falling with quantity, high productivity firms earn very little from a cost reduction as they already produce near the point where revenues are maximized. Indeed, I show that when assuming linear demand, high productivity firms never engage in domestic acquisitions. Instead, mid productivity firms, who are relatively less constrained by demand, purchase the assets of low productivity firms, who themselves stand to earn little in the market all together. This basic relationship matches the empirical patterns found in my companion work, Spearot (2012), where within North America firms listed in Compustat, mid productivity (sales per worker) firms are the most likely to invest.

An immediate corollary of this result is that high productivity firms must search elsewhere to expand profits via an acquisition. While this might include brand expansion - an option not addressed in this paper - acquiring for horizontal motives in other markets is also an option. ${ }^{5}$ Indeed, the paper shows that incentives to acquire for additional foreign market access are largest for high productivity firms. Hence, a foreign market, if sufficiently protected by trade costs, will be a suitable alternative for high productivity firms. In equilibrium, I show that when market access is important (high trade costs), high productivity firms acquire abroad motivated by market access, mid productivity firms acquire domestically motivated by cost reduction, and low productivity firms sell and exit. In contrast, when market access incentives are modest (small trade costs), high productivity firms are bid out of the acquisition market, and only mid productivity firms acquire. Overall, trade costs not only have a natural effect on the domestic-foreign composition of acquisition demand, but also have an effect on the qualitative features of how firms - especially high productivity firms - select into investment choices.

The policy relevant contribution of the paper is the way in which trade costs influence aggregate efficiency, and in particular, how a novel response of the acquisition market may overturn the

\footnotetext{
${ }^{4}$ For example, Campbell and Hopenhayn (2005), Foster, Haltiwanger, and Syverson (2008), and Feenstra and Weinstein (2010)

${ }^{5}$ Nocke and Yeaple (2006) model mergers and acquisitions as a form of expansion to additional varieties.
} 
canonical selection effects present in Melitz (2003). In particular, I close the traditional channel of selection, where the functional form of the model guarantees that all firms can profitably produce if they so choose (no fixed overhead costs). Instead, with an acquisition market, relatively unproductive firms may have an incentive to sell their assets to firms which are better able to utilize those assets. Given this transfer of resources from inefficient firms to more efficient firms, changes to the acquisition market have an effect on aggregate productivity.

The effect of trade costs on the composition of acquisition demand is intuitive: higher trade costs increase foreign acquisition demand, and decrease domestic acquisition demand. However, a novel contribution of the paper is to show how the resolution of this tension determines the effect of trade costs on aggregate productivity. In particular, I show that if firms optimally substitute between foreign acquisitions and no acquisitions, then trade liberalization may reduce aggregate productivity by reducing an important source of acquisition demand (foreign). Due to the demand issues summarized above, and the corresponding non-monotonic sorting of firms into acquisition choices, this occurs over many cases in my model. In a comparable model based on CES demand, this would occur only if acquisition demand was $100 \%$ foreign. Overall, the unique sorting of firms in this model opens up the door for a unique role of foreign firms in justifying non-zero tariffs on efficiency grounds.

\section{Related literature}

Broadly, this paper adds to the growing literature examining the role of firm heterogeneity in trade and investment decisions (Jovanovic and Rousseau, 2002; Nocke and Yeaple, 2007; Breinlich, 2008; Bustos, 2011). While the acquisition framework in the paper is particularly stylized, loosely based on neoclassical investment models such as Hayashi (1982), the results are much more general. The governing issue is that investment may affect variable efficiency, and when it does, the structure of demand is a crucial element that determines who invests and for what reason. Indeed, the results from this paper suggest that any firm heterogeneity model that examines investment in costreducing technologies or locations may be losing generality by using the convenient, but restrictive, CES demand assumption. ${ }^{6}$ Without cost improvements, demand issues would not be relevant and the model would be based solely on issues discussed in Brainard (1997), and deliver predictions similar to Helpman, Melitz, and Yeaple (2004).

In terms of the policy results, the role of foreign acquisitions in tempering and potentially reversing the positive effects of trade liberalization, to my knowledge, is entirely new. In particular, the results are in stark contrast with the canonical results from Melitz (2003) and Melitz and Ottaviano (2008) which do not include a foreign-domestic reallocation of resources. ${ }^{7}$ Indeed, the

\footnotetext{
${ }^{6}$ Examples of these models include Bustos (2011), Ederington and McCalman (2009)

${ }^{7}$ One notable exception is Nocke and Yeaple (2007), who derive a result in which trade liberalization can reduce aggregate productivity. However, their result is via a completely different mechanism which is not directly related to
} 
results may over-turn the long-run predictions in Melitz and Ottaviano (2008) depending on the importance of foreign acquisitions. This new relationship between foreign investment and trade barriers may also be relevant for models of FDI with tax and subsidy competition (Chisik and Davies, 2002; Chor, 2008; Glass and Saggi, 2010), especially when tax relief and subsidies explicitly target foreign investment.

In two ways, the results from the model sound a cautionary note regarding a number of empirical questions. First, the theoretical results of the paper suggest that non-parametric techniques are necessary to ascertain the relative productivity of exporters and/or firms that invest. This is particularly important when issues of market access may not be of first order importance, as in Head and Reis (2003). ${ }^{8}$ A similar point is made in Nocke in Yeaple (2007), where industry specific factors regarding the mobility of productivity have a strong influence on equilibrium firm behavior, and hence, regressions by industry-type may be more appropriate to evaluate trade and investment choices. Indeed, in my companion empirical work, I provide empirical evidence that the investment behavior at the heart of this paper is more likely to arise in industries with relatively high product differentiation. Second, at a more aggregate level, the possibility that reciprocal trade liberalization reduces aggregate productivity in the long-run seems at odds with a good portion of the empirical literature that documents productivity enhancing effects of trade liberalization. However, the paper itself motivates an extension related to the nuanced nature of this relationship, where if foreign acquisition demand is present and particularly footloose with respect to trade costs, then the traditional productivity enhancing nature of trade liberalization may be overturned. In this way, the paper motivates an interaction in the typical aggregate productivity regression between tariff cuts and the composition of investment demand. ${ }^{9}$

\section{Outline}

The rest of the paper is organized as follows. In section two, I develop the acquisition framework within a two country reciprocal markets model of product differentiation. In particular, I focus on the role of trade costs in determining the qualitative characteristics of acquisition incentives. In section three, I evaluate the effects of trade costs on the equilibrium sorting of firms into acquisition decisions, and the effect of trade costs on aggregate productivity. In section four, I briefly conclude.

foreign acquisition demand. Specifically, the result is driven by a margin between exporting and selling. Lower trade costs increase the profitability of exporting, which reduces the measure of inefficient firms that sell. This implies a productivity loss.

${ }^{8}$ For example, Head and Reis (2003) show using a sample of Japanese firms that when market access is relatively unimportant, high productivity firms choose not to invest in a low-wage country to serve the Japanese market.

${ }^{9}$ For the seminal Trefler (2004) paper evaluating CUSFTA, this issue would not be relevant, since as detailed in Breinlich (2008), 95\% of acquisitions were domestic within Canada. 


\section{Model}

The model itself consists of three stages. In stage one, entry decisions are made. Firm-level productivity is uncertain and each potential entrant is ex-ante identical. Firms enter until their expected post-entry profits are equal to the fixed cost of entry. Upon entry, firms receive a fixed "lump" of capital for use in their home market.

In stage two, firms realize their productivity and are allowed to trade assets on a perfectly competitive acquisition market in each country. As foreshadowed in the introduction, these assets will be cost-reducing in the sense that adding capital at a given location will improve variable factor productivity at that location. These assets may also provide additional market access if they are acquired in a market that is protected by trade barriers. Further particulars of the acquisition framework will be presented shortly.

Finally, in stage three, any capital accrued during the entry and acquisition stages is fixed, and firms only procure variable factors in the markets in which they own capital. Each active firm supplies its individual variety to the product market. Active firms are monopolists in their own variety, taking other industry variables as given.

The model is solved by backward induction, and will be introduced in this order.

\subsection{Product Market Equilibrium}

\section{Consumers}

To capture the standard features of the trade and investment literature as simply as possible, I assume that there are two countries which are identical in every dimension, with segmented markets for products (varieties) and assets. Consumers in each country have quasi-linear preferences over a differentiated industry and a numeraire good, $x_{0}$. Similar to Melitz and Ottaviano (2008), preferences of this sort can be written as:

$$
U=x_{0}+\theta \int_{i \in \Omega} q_{i} d i-\frac{1}{2} \eta\left(\int_{i \in \Omega} q_{i} d i\right)^{2}-\frac{1}{2} \gamma \int_{i \in \Omega}\left(q_{i}\right)^{2} d i
$$

In (1), $\Omega$ represents the measure of varieties, $q_{i}$ is the consumption of variety $i$, and the parameters $\theta(>0)$ and $\eta(>0)$ determine the substitution pattern between the differentiated industry and the numeraire. Finally, $\gamma(>0)$ represents the degree to which varieties are substitutable. If $\gamma$ were zero, all firms would price at the same level, since products would be homogeneous in the eyes of the consumer.

In each country, with $L$ consumers who each supply one unit of labor at a numeraire wage, the 
inverse demand function for variety $i$ can be derived as:

$$
p_{i}=\underbrace{\theta-\eta M \bar{q}}_{A}-\underbrace{\frac{\gamma}{L}}_{b} q_{i}=A-b q_{i}
$$

In (2), $p_{i}$ is the price of variety $i, M$ is the measure of all varieties sold in each product market, and $\bar{q}$ is the average quantity sold of each variety. Naturally, competition will be "tougher" when $M$ and/or $\bar{q}$ are high. Thus, the overall level of market "toughness" is captured in $A$, the residual demand level facing each firm. As all firms are small outside their own variety, firms take $A$ as given. In equilibrium, $A$ will be pinned down by a yet-to-be-presented free entry condition. Further, given the assumption of symmetry, $A^{\prime} s$ will be identical in each country, in equilibrium.

\section{Firms}

I assume a production framework in which acquisitions at a given location directly improve variablefactor productivity at that location. For the sake of tractability, adopting a framework similar to Perry and Porter (1985), the quadratic cost function of firm $i$ at location $j$ is:

$$
C\left(X_{i}^{j} \mid \alpha_{i}, K_{i}^{j}\right)=\frac{1}{2} \cdot \frac{\left(X_{i}^{j}\right)^{2}}{\alpha_{i} K_{i}^{j}}
$$

This cost-structure can be recovered from a Cobb-Douglas production function, given that the level of capital is fixed in the product market stage. ${ }^{10}$ In (3), $\alpha_{i}$ is firm-level productivity, and is continuously distributed according to $G(\alpha)$, defined over $\alpha \in(0, \infty)$. The variable $K_{i}^{j}$ represents capital accumulated during the initial stage and acquisition stage for firm $i$ at location $j$, and $X_{i}^{j}$ is production by firm $i$ at location $j$. Firm-level productivity is transferrable across all holdings of capital within the firm.

Focusing on a firm in the home market for the remainder of the paper, let $K_{i}^{H}$ and $K_{i}^{F}$ represent total capital holdings at home and foreign, respectively. Further, if the firm wishes to export to another market, a trade cost, $t$, is incurred per unit of exports. ${ }^{11}$ For any value of trade cost, each

\footnotetext{
${ }^{10}$ In stage three, firms only procure variable factors at a price $v$ per unit. The cost function is written as $C\left(L_{i}^{j} \mid v\right)=$ $v \cdot L_{i}^{j}$. With equal intensity of capital and variable factors, the Cobb-Douglas production function can be written as $X_{i}^{j}=\left(2 \alpha_{i} L_{i}^{j}\right)^{\frac{1}{2}}\left(K_{i}^{j}\right)^{\frac{1}{2}}$. Solving for $L_{i}^{j}$, and substituting into the above cost function, we get $C\left(X_{i}^{j} \mid \alpha_{i}, v, K_{i}^{j}\right)=$ $\frac{v}{2} \cdot \frac{\left(X_{i}^{j}\right)^{2}}{\alpha_{i} K_{i}^{j}}$. Normalizing $v$ to equal 1 gives the desired result, $C\left(X_{i}^{j} \mid \alpha_{i}, K_{i}^{j}\right)=\frac{1}{2} \cdot \frac{\left(X_{i}^{j}\right)^{2}}{\alpha_{i} K_{i}^{j}}$

${ }^{11}$ The basic intuition of the model applies to a case in which the trade cost is an ad-valorem tariff levied on export revenues.
} 
firm solves the following profit maximization problem:

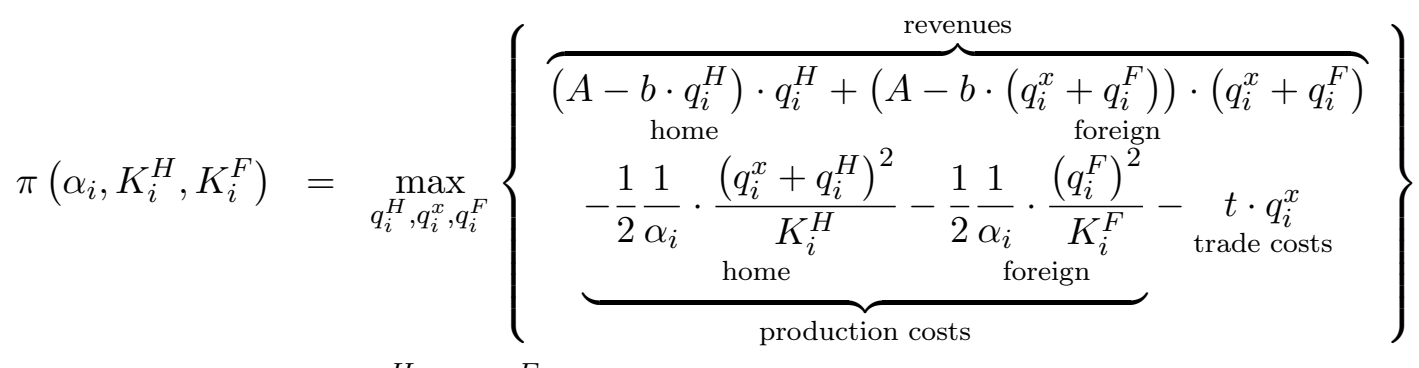

In (4), $q_{i}^{H}$ is home production of variety $i$ for sale in the home market, $q_{i}^{x}$ is home production of variety $i$ for sale in the foreign market, and $q_{i}^{F}$ is foreign production of variety $i$ for sale in the foreign market. These production levels are dictated by costs in each country, which are a function of the capital holdings of firm $i$ in each country, $K_{i}^{H}$ at home and $K_{i}^{F}$ abroad. These capital holdings will be determined in the acquisition stage. Note that I have written (4) such that no firms from home produce varieties abroad and export them back home. Given that countries are identical and foreign investment will incur an extra (soon-to-be described) fixed cost, firms will never have lower production costs abroad than at home, and thus will never profitably export from foreign to home. Thus, all foreign investment in this model will be of the horizontal variety. Lastly, one critical feature in (4) is that export production at home increases the costs of non-export production at home, and vice versa. This will be a particularly important feature when discussing foreign acquisitions.

Generally, if firms remain "domestic", in the sense that they purchase no foreign capital in the acquisition market $\left(K_{i}^{F}=0\right)$, optimal profits are written as:

$$
\pi\left(\alpha, K^{H}, 0\right)=\left\{\begin{array}{ll}
\frac{A^{2} \alpha K^{H}}{4 b \alpha K^{H}+2} & \alpha \leq \frac{t}{2 b K^{H}(A-t)} \\
\frac{A^{2} \alpha K^{H}}{2 b \alpha K^{H}+2}-\frac{t\left(4 b A \alpha K^{H}-2 b \alpha K^{H} t-t\right)}{4 b\left(2 b \alpha K^{H}+2\right)} & \alpha>\frac{t}{2 b K^{H}(A-t)}
\end{array}\right\}
$$

In (5), where $i^{\prime} s$ have been dropped for notational convenience, when $\alpha \leq \frac{t}{2 b K^{H}(A-t)}$, firms do not export. If a firm's productivity is too low, the maximum trade-cost adjusted marginal revenue of serving the foreign market is lower than the equilibrium marginal cost of only serving the domestic market. If $\alpha>\frac{t}{2 b k K^{H}(A-t)}$, the opposite is the case, where firms have low enough production costs such that additional domestic production intended for exports is optimal. ${ }^{12}$ Finally, note that exporting is not profitable for any firm if $t \geq A$. Thus, I henceforth restrict the parameter space to the range of non-prohibitive trade costs, $t<A$.

At this point, I must make a few assumptions regarding the nature of acquisitions that occur

\footnotetext{
${ }^{12}$ Note that this cutoff decreases as the level of domestic capital holdings, $K^{H}$, increases. Conditional on productivity, exporting is more likely when firms hold more capital at home.
} 
prior to stage three. For tractability, and since investment behavior tends to be "lumpy" (Doms and Dunne, 1998), I assume that capital from the entry stage is indivisible in the acquisition stage; firms may not buy or sell fractions of capital. Additionally, due to unmodeled organizational factors, I assume that a firm only has enough resources to acquire one firm in the acquisition stage. Thus, firms are restricted to four options: sell all capital and exit $(S)$, buy the capital of an exiting domestic firm $(B)$, buy the capital of an exiting firm in the foreign market $\left(B^{*}\right)$, or do nothing $(N)$. Finally, when a firm buys a unit of capital from another firm, it is unaffected by the productivity of the target.

Given these assumptions, product market profits of options $(N)$ and $(B)$ are defined as:

$$
\begin{aligned}
\pi^{N}(\alpha) & \equiv \pi(\alpha, k, 0) \\
\pi^{B}(\alpha) & \equiv \pi(\alpha, 2 k, 0)
\end{aligned}
$$

It is straightforward to show that $\pi^{B}(\alpha)>\pi^{N}(\alpha)>\frac{1}{2} \pi^{B}(\alpha)$. This implies that while acquisitions improve stage three profits, they do so at a diminishing rate. More specifics regarding the difference in $\pi^{B}(\alpha)$ and $\pi^{N}(\alpha)$ will be the focus of the next section.

Firms that purchase foreign capital $\left(B^{*}\right)$ hold $k$ units of capital at home, and $k$ units of capital abroad. Since firms have an equal amount of capital in each country (identical marginal cost curves), profit maximization will never include exports, and trade costs do not enter equilibrium profits. Hence, for firms that acquire abroad, profits in the product market are written as:

$$
\pi^{B^{*}}(\alpha) \equiv \pi(\alpha, k, k)=\frac{A^{2} \alpha k}{(2 b \alpha k+1)}
$$

It can be shown that $\pi^{B *}(\alpha)>\pi^{N}(\alpha) \geq \frac{1}{2} \pi^{B *}(\alpha)$. Like for domestic acquisitions, foreign acquisitions always increase stage three profits, and may exhibit diminishing returns. However, if absent the foreign acquisition exporting is not profitable, having identical units of capital at home and abroad simply replicates profits from home, which delivers the weak inequality.

\subsection{Acquisition Stage}

Given stage three profits, I now roll back to stage two and solve for optimal acquisition choices. Respectively, the profits of selling, doing nothing, buying domestic capital, and buying foreign capital, can be written as:

$$
\begin{aligned}
\Pi^{S}\left(R_{a}\right) & =R_{a} \\
\Pi^{N}(\alpha) & =\pi^{N}(\alpha) \\
\Pi^{B}\left(\alpha, R_{a}\right) & =\pi^{B}(\alpha)-R_{a} \\
\Pi^{B^{*}}\left(\alpha, R_{a}\right) & =\pi^{B^{*}}(\alpha)-R_{a}-\delta
\end{aligned}
$$


Firms pay an acquisition price $R_{a}$ for each lump of capital, where given the assumption of symmetry, $R_{a}$ will be the same in each country. The acquisition price will be pinned down in equilibrium by a market clearing condition. Finally, note that in the last equation, firms acquiring abroad pay an additional fixed cost of serving the foreign market, $\delta$. This is to embody the additional organizational, legal, or marketing costs associated with serving a foreign market.

A firm of productivity $\alpha$ chooses the acquisition option which maximizes profits in the acquisition market. Defining $V(\alpha)$ as optimal acquisition market profits, the acquisition choice problem is written as:

$$
V(\alpha)=\max \left\{R_{a}, \pi^{N}(\alpha), \pi^{B}(\alpha)-R_{a}, \pi^{B^{*}}(\alpha)-R_{a}-\delta\right\}
$$

Before precisely characterizing the relevant kinks in $V(\alpha)$, I will discuss the components of $V(\alpha)$ as they pertain to domestic and foreign acquisitions relative to the option of doing nothing.

\section{Domestic Acquisitions}

A firm will choose a domestic acquisition if it is superior to all other options after accounting for fixed costs. To begin the analysis, consider the change in profits for a firm that is choosing between domestic acquisitions and doing nothing. Precisely, this difference in profits is defined as follows:

$$
\begin{aligned}
\Delta \Pi(\alpha) & =\pi^{B}(\alpha)-\pi^{N}(\alpha) \\
& =\left\{\begin{array}{lrl}
\frac{A^{2} \alpha k}{2(2 b \alpha k+1)(4 b \alpha k+1)} & \text { if } & \leq \alpha<\frac{t}{4 b k(A-t)} \\
\frac{A^{2} \alpha k}{(2 b \alpha k+1)}-\frac{t(8 b A \alpha k-4 b \alpha k t-t)}{8 b(2 b \alpha k+1)}-\frac{A^{2} \alpha k}{(4 b \alpha k+2)} & \frac{t}{4 b k(A-t)} & \leq \alpha<\frac{t}{2 b k(A-t)} \\
\frac{A^{2} \alpha k}{2(b \alpha k+1)(2 b \alpha k+1)}-\frac{t k \alpha(4 A-t)}{8(b \alpha k+1)(2 b \alpha k+1)} & \frac{t}{2 b k(A-t)} & \leq \alpha
\end{array}\right\}
\end{aligned}
$$

As $\Delta \Pi(\alpha)$ is a rather involved function, which includes three piecewise (continuous) segments depending on whether a firm of productivity $\alpha$ can export before and/or after an acquisition, I will focus on a polar case to build intuition. ${ }^{13}$ Specifically, consider the case of free trade, $t=0$. Here, all firms can profitably export. Under this restriction, I can write $\Delta \Pi(\alpha)$ as:

$$
\Delta \Pi(\alpha \mid t=0)=\frac{A^{2} \alpha k}{2(b \alpha k+1)(2 b \alpha k+1)}
$$

\footnotetext{
${ }^{13}$ For low values of $\alpha$, firms cannot export before or after an acquisition. For firms in a middle range of productivity, the acquisition of additional capital provides the cost-improvement required to make exporting profitable. For high productivity firms, exporting is profitable before and after an acquisition. The incentives available to these firms are a combination of the incentives under free trade $\left(\frac{A^{2} \alpha k}{2(b \alpha k+1)(2 b \alpha k+1)}\right)$, and the negative effect of positive trade costs $\left(\frac{t k \alpha(4 A-t)}{8(b \alpha k+1)(2 b \alpha k+1)}\right)$
} 
In (9), it is straightforward to show that $\Delta \Pi(\alpha \mid t=0)$ approaches zero for low and high $\alpha$, and reaches its maximum on the interior at $\frac{\sqrt{2}}{2 b k}$. The intuition for this property is as follows. On one end of productivity, the least efficient firms are limited by an intrinsically steep marginal cost schedule. Whether or not they acquire a domestic lump of capital, they are still quite unproductive, and the absolute gains from a domestic acquisition are tiny. In contrast, the most efficient firms are constrained not by costs, but by the structure of market demand. Specifically, the highest productivity firms operate on a less-elastic portion of the demand curve, which limits the incentive to expand production after a cost-lowering acquisition. Firms in a mid-range of productivity are constrained by neither, and earn relatively high returns from a domestic acquisition. Thus, with linear demand, firms within a mid-range of productivity benefit the most from a cost-lowering domestic acquisition.

The following lemma proves that the incentives discussed above are relevant for the entire range of non-prohibitive trade costs.

Lemma 1 At the limits, $\Delta \Pi(0)=0$ and $\lim _{\alpha \rightarrow \infty} \Delta \Pi(\alpha)=0$. Further, there exists a productivity level $\widehat{\alpha}$ such that

$$
\begin{aligned}
& \frac{\partial \Delta \Pi(\alpha)}{\partial \alpha}>0 \text { if } \alpha<\widehat{\alpha} \\
& \frac{\partial \Delta \Pi(\alpha)}{\partial \alpha}<0 \text { if } \widehat{\alpha}<\alpha
\end{aligned}
$$

Proof. See Appendix

An interesting implication of Lemma 1 is that under a variable elasticity demand system as in Melitz and Ottaviano (2008), high productivity firms are not the firms most likely to invest in order to improve costs. Indeed, in a companion paper, Spearot (2012), I show using non-parameteric techniques and a conceptually similar measure of productivity that there is evidence of such behavior for North American firms. This result is in stark contrast to models using CES demand, such as Bustos (2011), where high productivity firms invest in new technology alongside investing in export market access. An interesting implication of my model is that high productivity firms, who are most likely to export (absent foreign acquisitions), would be among the least likely to invest in cost improving technology.

The intuition for Lemma 1 is more general than the specific demand and cost assumptions used in this paper. In the Online Appendix, I detail the marginal value of added capital as a function of productivity, where precisely, I show that the marginal value of domestic capital is increasing in productivity if $\epsilon_{M R^{H}, q^{H}}>-\frac{1}{1-\rho}$, where $\epsilon_{M R^{H}, q^{H}}$ is the elasticity of the marginal revenue curve in $H$ with respect to quantity, and $\frac{1}{1-\rho}(\rho \in(0,1))$ is the constant elasticity of substitution between capital and labor in the production function used to derive costs. Indeed, for any cost function derived from 
a constant elasticity of substitution production function, the marginal value of domestic capital is increasing in productivity only if the firm experiences a relatively small loss in revenue with increased production. For CES demand, this condition is always satisfied (where $\epsilon_{M R^{h}, q^{h}} \in(-1,0)$ ), but for linear, it is clearly not (where $\epsilon_{M R^{h}, q^{h}} \in(-\infty, 0)$ ).

\section{Foreign Acquisitions}

With domestic acquisitions, since all capital is in one location, the incentives to buy additional capital for the home market are based solely on cost-improvements through variable costs. In this section, I will examine how the added element of proximity influences acquisition decisions.

Precisely, define the profits from acquiring foreign capital relative to doing nothing as $\Delta \Pi^{*}(\alpha)=$ $\pi^{B^{*}}(\alpha)-\pi^{N}(\alpha)-\delta$. As a function of model parameters:

$$
\begin{aligned}
\Delta \Pi^{*}(\alpha) & =\pi^{B^{*}(\alpha)-\pi^{N}(\alpha)-\delta} \\
& =\left\{\begin{array}{ll}
\frac{A^{2} \alpha k}{2(2 b \alpha k+1)}-\delta & \alpha \leq \frac{t}{2 b k(A-t)} \\
\frac{A^{2} \alpha k}{2(b \alpha k+1)(2 b \alpha k+1)}-\delta+\frac{t(4 b A \alpha k-2 b \alpha k t-t)}{8 b(b \alpha k+1)} & \alpha>\frac{t}{2 b k(A-t)}
\end{array}\right\}
\end{aligned}
$$

To build intuition over $\Delta \Pi^{*}(\alpha)$, we can once again evaluate the polar case of free trade. Precisely, under free trade, $\Delta \Pi^{*}(\alpha)$ is written as:

$$
\Delta \Pi^{*}(\alpha \mid t=0)=\frac{A^{2} \alpha k}{2(b \alpha k+1)(2 b \alpha k+1)}-\delta
$$

Note that in (11), aside from the fixed costs of foreign investment, the incentives under free trade are exactly the same for foreign acquisitions as they are for domestic acquisitions. Hence, for this case, when market access considerations are nil $(t=0)$, mid productivity firms have the highest incentive to acquire foreign capital. The intuition for this feature will be discussed shortly, though the key is that even without market access incentives, acquiring foreign capital allows the firm to divert export production to a new foreign affiliate. Since lower production at home decreases average variable costs at home, a foreign acquisition results in a domestic cost improvement. Indeed, this result is also more general relative to the assumptions used in this paper, where in the online appendix I show using flexible assumptions over demand and costs that the optimal levels of foreign and domestic capital are maximized at the same value of productivity when trade costs are zero.

In contrast, consider the equation for $\Delta \Pi^{*}(\alpha)$ when trade costs are prohibitively large $(t=A)$ :

$$
\Delta \Pi^{*}(\alpha \mid t=A)=\frac{A^{2} \alpha k}{2(2 b \alpha k+1)}-\delta
$$

Here, market access considerations are maximized since all trade is prohibitive. Further, for this 
same reason, there is no export production to divert upon purchasing a foreign plant. Hence, in contrast with (11), $\frac{\partial \Delta \Pi^{*}(\alpha \mid t=A)}{\partial \alpha}>0$ for all $\alpha$.

The balance between incentives for market access and incentives for cost reduction are formalized in the following Lemma, which summarizes the relevant properties of $\Delta \Pi^{*}(\alpha)$ over the entire range of trade costs:

Lemma 2 If $t<\frac{2}{2+\sqrt{2}} A$, there exists an $\widehat{\alpha}^{*}$ such that:

$$
\begin{aligned}
& \frac{\partial \Delta \Pi^{*}(\alpha)}{\partial \alpha}>0 \text { if } \alpha<\widehat{\alpha}^{*} \\
& \frac{\partial \Delta \Pi^{*}(\alpha)}{\partial \alpha}<0 \text { if } \alpha>\widehat{\alpha}^{*}
\end{aligned}
$$

Conversely, if $t \geq \frac{2}{2+\sqrt{2}} A$, then

$$
\frac{\partial \Delta \Pi^{*}(\alpha)}{\partial \alpha}>0 \text { for all } \alpha
$$

Further, $\Delta \Pi^{*}(0)=-\delta$, and $\lim _{\alpha \rightarrow \infty} \Delta \Pi^{*}(\alpha)=\frac{(2 A-t) t}{4 b}-\delta$.

Proof. See Appendix

Lemma 2 is an entirely novel result, and one which is central to the open economy features of the model. It states that if trade costs are low $\left(t<\frac{2}{2+\sqrt{2}} A\right)$, mid productivity firms will have the highest incentive to acquire a foreign firm. In contrast, for high trade costs $\left(t \geq \frac{2}{2+\sqrt{2}} A\right)$, high productivity firms have the highest incentive to acquire a foreign firm.

The intuition for this result is best explained by how trade costs affect incentives for market access and variable factor efficiency. If trade costs are non-zero, purchasing a foreign firm always provides additional market access. Similar to Helpman, Melitz, and Yeaple (2004), the incentive to gain additional market access is increasing in productivity. High productivity firms are the largest exporters, and given that exporting costs are independent of productivity, these firms have the highest incentive to avoid these costs. Thus, absent any other incentives, high productivity firms always have the largest incentive to acquire abroad.

However, in this particular model, there are additional incentives on the cost-side that motivate foreign acquisitions. Not only does purchasing a foreign firm provide additional market access, but it will divert export production that would otherwise be produced at home. Critically, given a fixed amount of capital at home, lower production at home decreases the average variable cost of producing at home. ${ }^{14}$ Hence, by acquiring foreign capital, a firm can reduce domestic production costs in a fashion similar to a domestic acquisition. And, as has been discussed for the case of domestic acquisitions, mid productivity firms have the highest incentive to reduce production costs when absolute elasticities fall sufficiently in quantities.

\footnotetext{
${ }^{14}$ This is a general feature of constant-returns production functions in which (1) factors relate positively with output, and (2) factors are substitutable (though not perfectly substitutable). See the Online Appendix.
} 
Figure 1: Acquisition Incentives - Open Economy

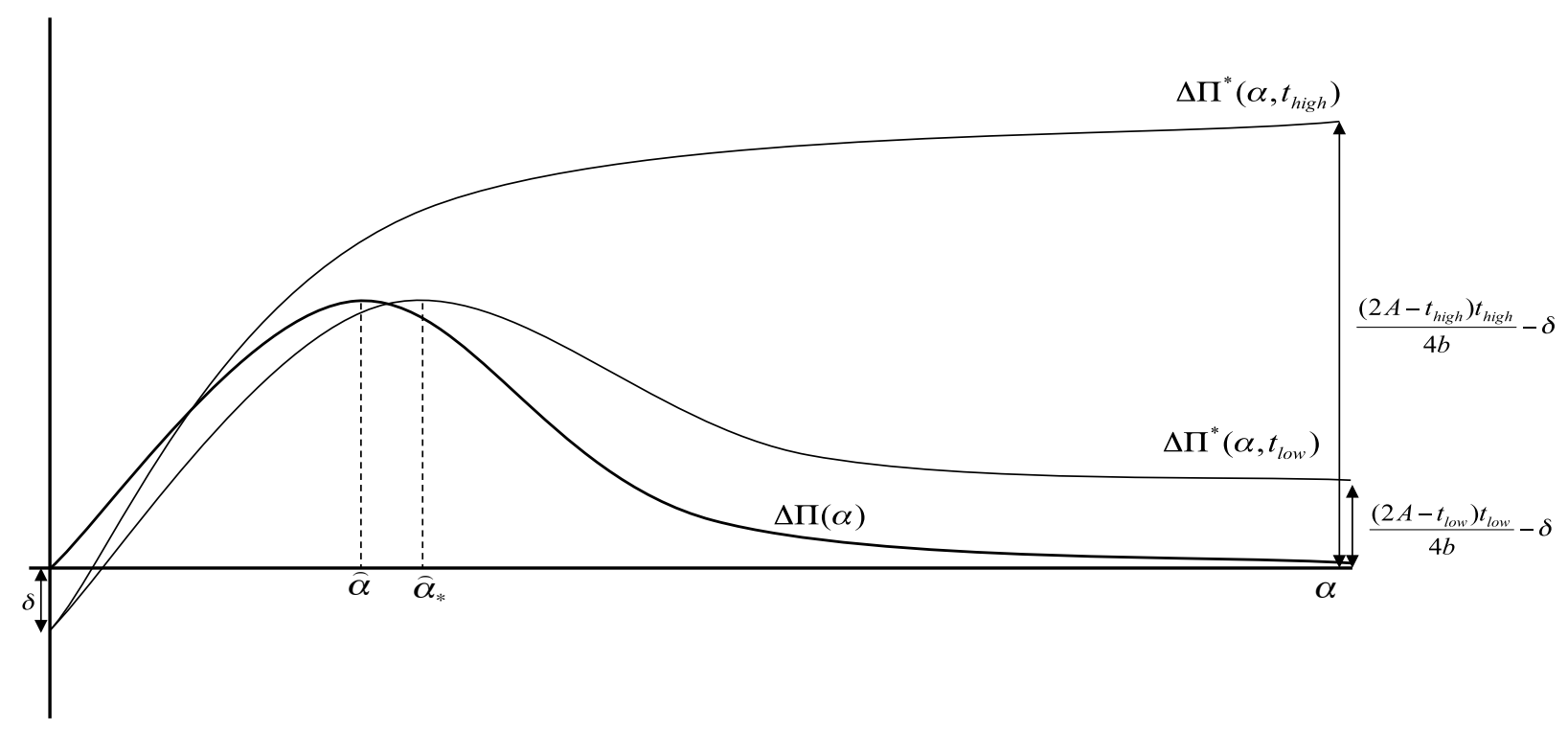

Thus, the central issue is whether market access (proximity) or production cost (concentration) considerations dominate. As characterized in Lemma 2, the relative size of trade costs provides a resolution to this issue. This is illustrated in Figure 1. When trade costs are relatively high ( $t_{\text {high }}$ in Figure 1), exports are relatively low, and the incentives to gain additional market access dominate. Thus, high productivity firms have the highest incentive to acquire abroad. In contrast, when trade costs are low ( $t_{\text {low }}$ in Figure 1$)$, foreign sales via exports are already significant and the incentives to gain additional market access are modest. Hence, the incentives to reduce production costs are now relatively large, and mid productivity firms have the highest incentive to acquire abroad

Essentially, one can think of foreign acquisitions as a skewed version of domestic acquisitions. If trade costs are zero, they function identically to domestic acquisitions, (except for the fixed cost $\delta)$. However, as trade costs increase, the incentives to acquire a foreign firm become skewed toward firms of higher productivity. Eventually, if trade costs are high enough, the incentive to acquire a foreign firm is an increasing function in productivity, and looks nothing like the incentive to acquire a domestic firm. 


\section{Optimal Acquisition Choice}

With acquisition incentives in-hand, I will characterize the indifference points in $V(\alpha)$ as they pertain to the choice between selling, doing nothing, acquiring domestically, and acquiring abroad. First, I will evaluate preferences over $S, N$, and $B$. Then, I will do the same for $S, N$, and $B^{*}$. Finally, I evaluate preferences over $B$ and $B^{*}$.

To simplify the presentation of indifference conditions, and the productivity cutoffs that define these conditions, I will assume parameter values such that no outcome is trivially unprofitable relative to the acquisition price. Specifically, I will assume that $\max \Delta \Pi(\alpha)>R_{a}$ and $\max _{\alpha} \Delta \Pi^{*}(\alpha)>R_{a}$. Both conditions can be relaxed, though at the expense of a more cluttered presentation.

To begin, firms are indifferent between doing nothing and selling at $\alpha_{S}$. This cutoff is defined by the following:

$$
\pi^{N}\left(\alpha_{S}\right)=R_{a}
$$

where,

$$
\text { For } \alpha<\alpha_{S}, S \succ N
$$

Firms prefer selling if the acquisition price is greater than the return from staying in the market. This is the case for low productivity firms, who earn relatively little in the product market when compared to the acquisition price.

At $\underline{\alpha}_{B}$ and $\bar{\alpha}_{B}$, firms are indifferent between doing nothing and buying domestic capital. Precisely:

$$
\begin{aligned}
& \Delta \Pi\left(\underline{\alpha}_{B}\right)=R_{a} \\
& \Delta \Pi\left(\bar{\alpha}_{B}\right)=R_{a}
\end{aligned}
$$

where,

$$
\text { For } \alpha \in\left(\underline{\alpha}_{B}, \bar{\alpha}_{B}\right), B \succ N
$$

As foreshadowed in Lemma 1, relative to doing nothing, only mid productivity firms prefer to acquire domestic capital. The following Proposition summarizes the relative position of the productivity cutoffs $\alpha_{S}, \underline{\alpha}_{B}$ and $\bar{\alpha}_{B}$, and the implications this has for the choice between selling, domestic acquisitions, and doing nothing. 
Proposition 1 The choice between selling (S), doing nothing (N), and domestic acquisitions (B) can be characterized as follows:

$$
\text { For } \begin{aligned}
& \alpha \in\left(0, \alpha_{S}\right), \text { firms prefer } S \text { to } N \text { and } B \\
& \alpha \in\left[\alpha_{S}, \underline{\alpha}_{B}\right], \text { firms prefer } N \text { to } S \text { and } B \\
& \alpha \in\left(\underline{\alpha}_{B}, \bar{\alpha}_{B}\right), \text { firms prefer } B \text { to } N \text { and } S \\
& \alpha \in\left[\bar{\alpha}_{B}, \infty\right), \text { firms prefer } N \text { to } S \text { and } B
\end{aligned}
$$

Proof. See Appendix

Moving forward, I now characterize the indifference points in $V(\alpha)$ between foreign acquisitions and doing nothing. From Lemma 2, we see that the shape of $\Delta \Pi^{*}(\alpha)$ is critically dependent on the value of trade costs. For low $t$, the upper and lower limits of $\Delta \Pi^{*}(\alpha)$ are tiny (and possibly negative), with a maximum at a mid value of $\alpha$. In contrast, for high $t, \Delta \Pi^{*}(\alpha)$ is strictly increasing in $\alpha$. Hence, when $t$ is relatively low, there exists the possibility of two productivity cutoffs at which firms are indifferent between doing nothing and acquiring abroad. In contrast, when $t$ is relatively high, there will be at most one indifference point.

To put more structure on the choice between foreign acquisitions and doing nothing, first suppose that $\lim _{\alpha \rightarrow \infty} \Delta \Pi^{*}(\alpha)<R_{a}$. Here, the upper and lower limits of $\Delta \Pi^{*}(\alpha)$ are below the acquisition price. For this case, define $\underline{\alpha}_{B^{*}}$ and $\bar{\alpha}_{B^{*}}$ as the productivity levels at which firms are indifferent between foreign acquisitions and doing nothing. Precisely, these two cutoffs are defined by:

$$
\begin{aligned}
& \Delta \Pi^{*}\left(\underline{\alpha}_{B^{*}}\right)=R_{a} \\
& \Delta \Pi^{*}\left(\bar{\alpha}_{B^{*}}\right)=R_{a}
\end{aligned}
$$

where,

$$
\text { For } \alpha \in\left(\underline{\alpha}_{B^{*}}, \bar{\alpha}_{B^{*}}\right), B^{*} \succ N
$$

Next, in contrast with the previous case, assume that $\lim _{\alpha \rightarrow \infty} \Delta \Pi^{*}(\alpha)>R_{a}$. Here, the parameters of the model are such that the upper limit of $\Delta \Pi^{*}(\alpha)$ is above the acquisition price. In this case, there exists a unique productivity level, $\underline{\alpha}_{B^{*}}$, at which firms are indifferent between foreign acquisitions and doing nothing. Precisely,

$$
\Delta \Pi^{*}\left(\underline{\alpha}_{B^{*}}\right)=R_{a}
$$

where,

$$
\text { For } \alpha \in\left(\underline{\alpha}_{B^{*}}, \infty\right), B^{*} \succ N
$$

Again, this case is more likely when $t$ is high.

The preference conditions between selling, doing nothing, and foreign acquisitions are proven in 
the following Proposition.

Proposition 2 The choice between selling $(S)$, no acquisitions $(N)$, and foreign acquisitions $\left(B^{*}\right)$ can be summarized as follows:

$$
\begin{aligned}
& \text { If } \lim _{\alpha \rightarrow \infty} \Delta \Pi^{*}(\alpha)<R_{a} \text {, then } \\
& \text { For } \alpha \in\left(0, \alpha_{S}\right) \text {, firms prefer } S \text { to } N \text { and } B^{*} \\
& \alpha \in\left[\alpha_{S}, \underline{\alpha}_{B^{*}}\right] \text {, firms prefer } N \text { to } S \text { and } B^{*} \\
& \alpha \in\left(\underline{\alpha}_{B^{*}}, \bar{\alpha}_{B^{*}}\right) \text {, firms prefer } B^{*} \text { to } S \text { and } N \\
& \alpha \in\left[\bar{\alpha}_{B^{*}}, \infty\right) \text {, firms prefer } N \text { to } S \text { and } B^{*} \\
& \text { If } \lim _{\alpha \rightarrow \infty} \Delta \Pi^{*}(\alpha)>R_{a} \text {, then } \\
& \text { For } \alpha \in\left(0, \alpha_{S}\right) \text {, firms prefer } S \text { to } N \text { and } B^{*} \\
& \alpha \in\left[\alpha_{S}, \underline{\alpha}_{B^{*}}\right] \text {, firms prefer } N \text { to } S \text { and } B^{*} \\
& \alpha \in\left(\underline{\alpha}_{B^{*}}, \infty\right) \text {, firms prefer } B^{*} \text { to } S \text { and } N
\end{aligned}
$$

Proof. See appendix.

In Proposition 2, the preference conditions between selling, doing nothing, and acquiring a foreign firm are a function of the relative shape of $\Delta \Pi^{*}(\alpha)$ around $R_{a}$, which is ultimately a function of the relative value of trade costs. That is, when $t$ is small and the incentives to avoid trade costs are low, mid productivity firms are the only firms that prefer a foreign acquisition to doing nothing. Since high productivity firms have a negligible incentive to invest for market access, they prefer doing nothing when $t$ is low. In contrast, when $t$ is high and the incentives to avoid trade costs are high - especially for high productivity firms - the only firms that prefer a foreign acquisition to doing nothing are high productivity firms.

Propositions 1 and 2 describe the indifference conditions of each acquisition option, respectively, relative to doing nothing and selling. I now compare foreign acquisitions and domestic acquisitions to one another. Precisely, the indifference point between foreign and domestic acquisitions, $\alpha_{B B^{*}}$, is implicitly defined by:

$$
\Delta \Pi^{*}\left(\alpha_{B B^{*}}\right)=\Delta \Pi\left(\alpha_{B B^{*}}\right)
$$

The relationship between $\Delta \Pi^{*}(\alpha)$ and $\Delta \Pi(\alpha)$, and the indifference conditions defined around $\alpha_{B B^{*}}$, are proven in the following Lemma: 
Proposition 3 If $t>0$, The value of foreign acquisitions relative to domestic acquisitions is increasing in productivity:

$$
\frac{\partial \Delta \Pi^{*}(\alpha)}{\partial \alpha}>\frac{\partial \Delta \Pi^{*}(\alpha)}{\partial \alpha}
$$

Further,

$$
\lim _{\alpha \rightarrow \infty}\left(\Delta \Pi^{*}(\alpha)-\Delta \Pi(\alpha)\right)=\frac{(2 A-t) t}{4 b}-\delta
$$

Hence, if $\frac{(2 A-t) t}{4 b}>\delta, B^{*} \succ B$ if $\alpha>\alpha_{B B^{*}}$. If $\frac{(2 A-t) t}{4 b}<\delta, B \succ B^{*}$ for all $\alpha$.

Proof. See Appendix.

In Proposition 3, when comparing domestic acquisitions and foreign acquisitions, the highest productivity firms are more likely to prefer a foreign acquisition to a domestic acquisition. Intuitively, as they are larger potential exporters, higher productivity firms have a larger incentive to avoid trade costs by owning equal amounts of capital at home and abroad. However, there do exist parameter values $\left(\frac{(2 A-t) t}{4 b}<\delta\right)$ such that domestic acquisitions are always preferred relative to foreign acquisitions. In this case, the maximum incentive to avoid trade costs $\left(\frac{(2 A-t) t}{4 b}\right)$ is less than the added fixed cost of foreign investment $(\delta)$.

An interesting corollary of Proposition 3 is that for the productivity level at which the incentives to acquire domestic capital are maximized, the incentives to acquire foreign capital are still increasing in productivity. In the Online Appendix, I prove this same result assuming a general demand function and cost functions derived from a constant elasticity production function. Indeed, when $t>0$ the marginal incentive to purchase foreign capital is still increasing in productivity when the marginal incentive purchase domestic capital has been maximized. This highlights the general role of market access in skewing the incentives to acquire toward higher productivity firms.

To pin-down optimal acquisition choice, I must compare the values of $\underline{\alpha}_{B}, \bar{\alpha}_{B}, \underline{\alpha}_{B^{*}}, \bar{\alpha}_{B^{*}}$, and $\alpha_{B B^{*}}$, and the corresponding preference relationships in Propositions 1-3. To build intuition over the relative values of $\alpha$, I first discuss two polar cases in which there are relatively small trade and investment costs. ${ }^{15}$ First, consider the case in which $\delta$ is small and positive, but $t=0$. By Proposition 3, domestic acquisitions are always preferred to foreign acquisitions $\left(0=\frac{(2 A-t) t}{4 b}<\delta\right)$ and $\alpha_{B B^{*}}$ is not defined. For the other productivity cutoffs, it is the case that $\underline{\alpha}_{B}<\underline{\alpha}_{B^{*}}<\bar{\alpha}_{B^{*}}<$ $\bar{\alpha}_{B}$. Even though the marginal incentives for each type of investment are the same when $t=0$, the fixed $\operatorname{cost} \delta$ shifts down the incentives for foreign acquisitions and reduces the range for which foreign acquisitions are profitable (though not necessarily optimal). Overall, domestic acquisitions are more profitable than foreign for all firms when $\delta$ is positive and $t$ is zero.

In contrast, consider the case in which $t$ is small but positive and $\delta=0$. In this case, by the slope condition in Proposition 3, foreign acquisitions are preferred to domestic for all values of $\alpha>0$,

\footnotetext{
${ }^{15}$ This is solved analytically in an older working paper available on the author's website.
} 
Figure 2: Optimal Acquisition Choice - Example

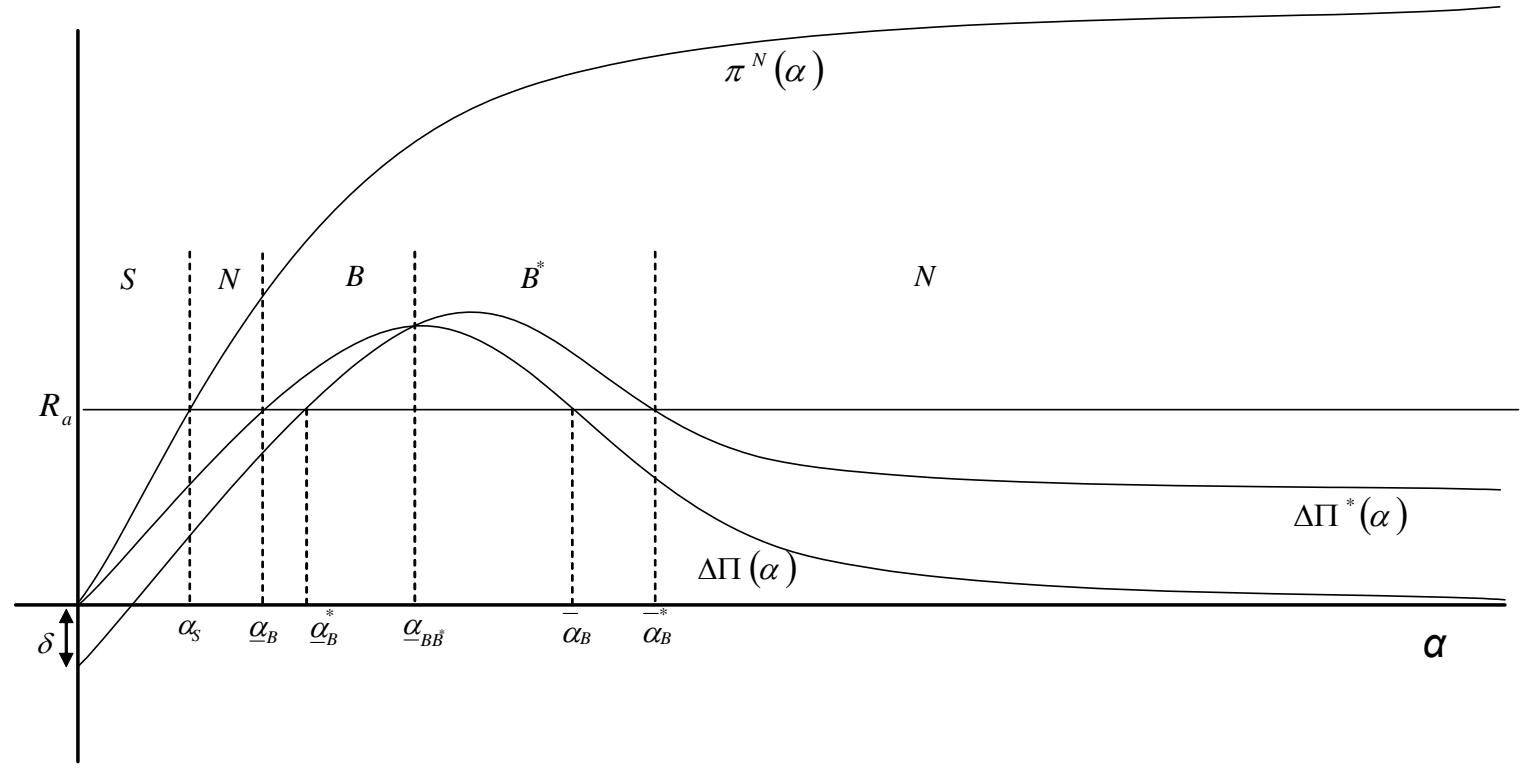

and hence, the ranking of productivity cutoffs is $0=\alpha_{B B^{*}}<\underline{\alpha}_{B^{*}}<\underline{\alpha}_{B}<\bar{\alpha}_{B}<\bar{\alpha}_{B^{*}}$. Here, there are no fixed costs to shift down the incentives for foreign acquisitions, but small positive trade costs that increase the incentive for a foreign acquisition relative to domestic at all levels of productivity for which exporting is profitable. When trade costs are small but positive, incentives for foreign acquisitions shift up at the cutoffs, and the range of productivity for which foreign acquisitions are profitable is now larger than the range for domestic acquisitions.

Outside of these polar cases, there are many possible rankings of $\underline{\alpha}_{B}, \bar{\alpha}_{B}, \underline{\alpha}_{B^{*}}, \bar{\alpha}_{B^{*}}$, and $\alpha_{B B^{*}}$ that depend on the relative values of $t, \delta$, and how the underlying productivity distribution affects the market clearing price for assets. All possible sortings into acquisition choices are presented in Appendix A. However, to build additional intuition, the novel features of the acquisition model are displayed in Figure 2, where I have illustrated one possible solution to the acquisition choice problem for a specific pair of $t$ and $\delta$ in which both domestic and foreign acquisitions occur, and there exists a continuous region of acquisition activity in $\alpha$. In Figure 2, the least productive firms choose to sell and exit. Firms in a mid-range of productivity find some type of acquisition profitable, where the most-efficient firms within this group prefer foreign acquisitions. Of the remaining active firms, the least productive and most productive choose to do nothing in the acquisition market. For the highest productivity firms, even though they have the highest incentive to avoid trade costs, these incentives are not sufficient to compensate for the acquisition price, which itself has been bid-up by mid productivity firms primarily for purposes of cost reduction.

A novel feature of Figure 2 is that the set of firms that acquire domestically and the set of 
firms that acquire abroad are non-nested. In other words, acquiring domestically is not the next best option for every firm that acquires abroad, and vice versa. For some firms, the next best option to a domestic or foreign acquisition is no acquisition. The crucial implication of this feature for the forthcoming policy analysis is that there exists a new margin through which firms can substitute between foreign acquisitions and no acquisitions, thus affecting total acquisition demand. For example, in response to higher trade costs, if $\bar{\alpha}_{B^{*}}$ is defined, it will rise into the region of productivity which supports no acquisitions. As foreign acquisitions and domestic acquisitions respond differently to trade costs, an active margin of substitution between foreign acquisitions and no acquisitions will facilitate a novel relationship between trade costs and aggregate productivity.

Figure 2 also describes a novel pattern of trade and investment. That is, exporters are not necessarily less productive than those firms investing abroad. This suggests that in relatively integrated markets, such that the costs of international commerce are low, exporters should be the most productive. On a basic level, this prediction may seem counterintuitive since the most productive firms tend to have the largest incentive to avoid trade costs. However, if trade costs are relatively low, this incentive is relatively small compared to the benefits mid-productivity firms can earn from acquisitions that are primarily for cost reduction. Hence, when trade costs are low, high-productivity firms are bid out of both the domestic and foreign acquisition markets, and choose to export instead.

Finally, these novel relationships could be interesting predictions to test in future work using detailed census data, where the relationship between productivity and investment choices depends on industry specific factors. A similar point is made in Nocke in Yeaple (2007), where industry specific factors regarding the mobility of productivity have a strong influence on qualitative equilibrium firm behavior. The analogous result in this paper is that the basic characteristics of cost-structure and demand at the industry level motivate a similar degree of care in approaching empirical work. Indeed, one could use industry-specific regressions and non-parametric methods to evaluate the probability of investment and exporting as function of productivity. As detailed by the above model, industries in which markets are relatively integrated and exhibit product differentiation may yield a non-monotone relationship between investment or the probability of exporting and productivity. Indeed, the companion work in Spearot (2012) provides evidence that the non-monotone investment behavior at the heart of this paper is present within a sample of North American firms for more differentiated industries (though unable to distinguish between domestic and foreign investment).

\subsection{Equilibrium}

To close the model, I now characterize the industry equilibrium components of the acquisition market, $R_{a}$ and $A$. Despite the rich and diverse possibilities of acquisition behavior, I can show that there exists a unique solution for both of these aggregate measures, and thus, a unique solution

to the acquisition market itself. For the sake of simplicity, let $\Theta_{S}$ represent the measure of firms 
that sell and exit the market, and let $\Theta_{B}$ and $\Theta_{B^{*}}$ represent the measure of firms that buy domestic and foreign capital, respectively. Note that $\Theta_{B^{*}}$ may only be comprised of one productivity cutoff, and that either $\Theta_{B}$ and $\Theta_{B^{*}}$ may be empty. Finally, let $\Theta_{N}$ represent the measure of firms that choose not to participate in the acquisition market.

Subject to firm-level acquisition decisions, the acquisition market must clear. Formally, this condition is written as:

$$
\overbrace{\int_{\alpha \in \Theta_{B}} d G(\alpha)+\int_{\alpha \in \Theta_{B^{*}}} d G(\alpha)}^{\text {Demand }}=\overbrace{\int_{\alpha \in \Theta_{S}} d G(\alpha)}^{\text {Supply }}
$$

It is straightforward to show that there exists a unique acquisition market clearing price, $R_{a}>0$. This proof is presented in Appendix A. Since it is guaranteed that $R_{a}(A)>0$, it must be the case that either $\Theta_{B}$ or $\Theta_{B^{*}}$ remain non-empty. That is, some acquisitions always occur in equilibrium. However, it is not necessary that both are non-empty; either domestic or foreign acquisitions may not occur in equilibrium

The aggregate demand level $A$ is determined by a free entry condition. The free entry condition in each country is written as:

$$
\int_{0}^{\infty} V(\alpha) d G(\alpha)=F_{E}
$$

Via (24), there exists a unique value of $A$ provided that fixed entry costs are not prohibitively high. A sketch of this proof is available in Appendix A. ${ }^{16}$ Once $A$ is pinned down, given the equilibrium acquisition behavior, one can then solve for the unique measure of entering firms, $M_{E}$, using (2).

\section{Trade Liberalization}

In this section, I evaluate the effect of trade costs on acquisition behavior, where I begin by showing that trade costs have an intuitive effect on the composition of domestic and foreign acquisitions. I then examine the effect trade costs on aggregate productivity through the acquisition market. In particular, I show that the degree to which liberalization of trade barriers improves aggregate productivity depends crucially on whether there exists an active margin through which firms substitute between foreign acquisitions and no acquisitions.

\subsection{Acquisitions and Trade liberalization}

To examine the effect of trade costs on firm-level decisions and aggregate measures, I have chosen to conduct a number of simulation exercises. The details of the simulation are contained in the

\footnotetext{
${ }^{16} \mathrm{~A}$ full proof is available in an older working paper on the author's website
} 
Table 1: Equilibrium outcomes in Figure 3

\begin{tabular}{clllll}
\hline \hline Case & Sorting & $\Theta_{N}$ & $\Theta_{B}$ & $\Theta_{B^{*}}$ & Acq. Demand \\
\hline Domestic & $S, N, B, N$ & $\left(\alpha_{S}, \underline{\alpha}_{B}\right) \cup\left(\bar{\alpha}_{B}, \infty\right)$ & $\left(\underline{\alpha}_{B}, \bar{\alpha}_{B}\right)$ & $\emptyset$ & $G\left(\bar{\alpha}_{B}\right)-G\left(\underline{\alpha}_{B}\right)$ \\
Mixed-Mid & $S, N, B, B^{*}, N$ & $\left(\alpha_{S}, \underline{\alpha}_{B}\right) \cup\left(\bar{\alpha}_{B^{*}}, \infty\right)$ & $\left(\underline{\alpha}_{B}, \alpha_{B B^{*}}\right)$ & $\left(\alpha_{B B^{*}}, \bar{\alpha}_{B^{*}}\right)$ & $G\left(\bar{\alpha}_{B^{*}}\right)-G\left(\underline{\alpha}_{B}\right)$ \\
Mixed-High & $S, N, B, B^{*}$ & $\left(\alpha_{S}, \underline{\alpha}_{B}\right)$ & $\left(\underline{\alpha}_{B}, \alpha_{B B^{*}}\right)$ & $\left(\alpha_{B B^{*}}, \infty\right)$ & $1-G\left(\underline{\alpha}_{B}\right)$ \\
Foreign & $S, N, B^{*}$ & $\left(\alpha_{S}, \underline{\alpha}_{B}\right)$ & $\emptyset$ & $\left(\underline{\alpha}_{B^{*}}, \infty\right)$ & $1-G\left(\underline{\alpha}_{B^{*}}\right)$ \\
\hline
\end{tabular}

Notes: This table details the four equilibrium outcomes used for the simulation in Figures 3 and 4. "Sorting" details the sorting of firms in increasing order of productivity. All seven possible outcomes are detailed in the appendix.

appendix. While I choose to use simulations to make a clear and concise point, the model is solved rigorously in a technical appendix. ${ }^{17}$

To begin, I will detail the four equilibrium cases that I use to discuss the effect of trade costs on the acquisition market. These cases are presented in Table 1. The effects of trade costs on the acquisition equilibrium for these cases are illustrated in Figure 3. Focusing on the region labeled "Domestic", trade costs are relatively low compared with the fixed cost of foreign investment $(\delta)$, and hence, only domestic acquisitions occur. Further, the scale of domestic acquisition activity falls with trade costs. The intuition is that trade costs reduce the effective size of the world market. As a smaller market reduces in the incentive to acquire another firm, acquisition demand falls, pushing down the equilibrium acquisition price, resulting in fewer inefficient firms selling. This is exactly the response discussed in Breinlich (2008). Indeed, Breinlich also tests this prediction on a firm-level sample of US and Canadian firms, where the response of the acquisition market to trade costs is confirmed in the data. That is, trade liberalization expands acquisition activity. However, one important feature within the US-Canada case study is that domestic acquisitions comprise roughly $95 \%$ of all acquisitions. Thus, Breinlich's empirical work is well motivated by a model with only domestic acquisitions. Hence, the question arises - what are the theoretical predictions (and empirical implications) of a setting in which foreign acquisitions are more prominent?

Next, focus attention on "Mixed-Mid" in Figure 3. Here, we have a case in which trade costs are now large enough to support acquisitions abroad, though parameters of the model are such that acquisitions only occur within a mid-range of productivity. As trade costs increase, the measure of firms which choose domestic acquisitions $\left(\underline{\alpha}_{B}, \alpha_{B B^{*}}\right)$ continues to shrink while the measure of firms which choose foreign acquisitions $\left(\alpha_{B B^{*}}, \bar{\alpha}_{B^{*}}\right)$ widens (from nothing). Thus, within the middle region of Figure 3, the share of foreign acquisitions increases with higher trade costs. However, it is important to note that while trade costs have an intuitive effect on the foreign share of acquisitions, there is an ambiguous effect on total acquisition activity. This is due to $\bar{\alpha}_{B^{*}}$ rising into regions of higher productivity, and is a direct result of the equilibrium sorting of firms. In a comparable CES demand model, this margin of adjustment would not be present, and total acquisition activity

\footnotetext{
${ }^{17}$ For analytical results of model with small $t$ and small $\delta$, please see the working paper version of the paper available at the author's website.
} 
Figure 3: Equilibrium Acquisition Choice and Trade Costs

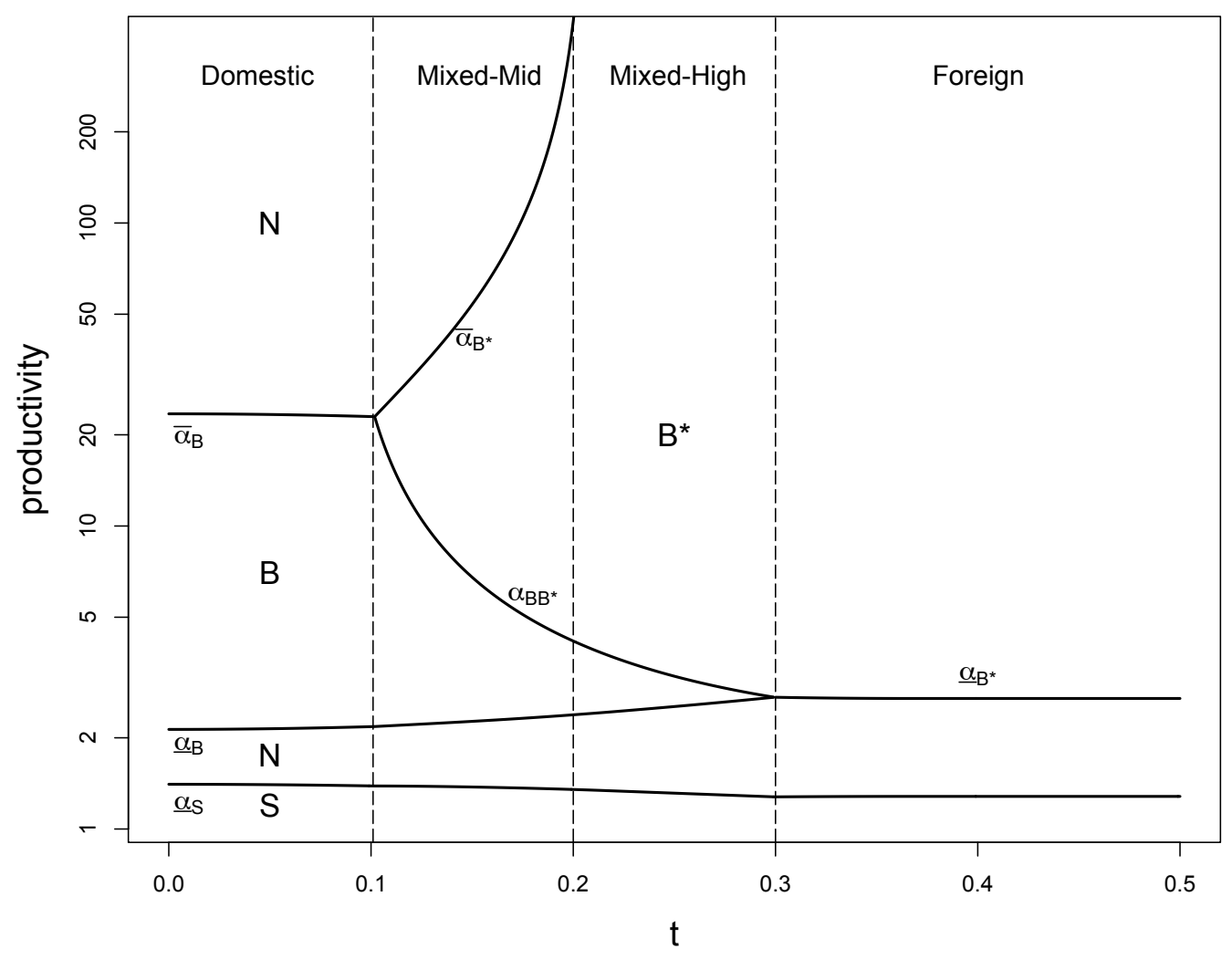

would fall with higher trade costs. This is apparent in "Mixed-High", where relatively high values of $t$ yield a case in which $\bar{\alpha}_{B^{*}}$ is no longer defined. Here, the region of $B\left(\underline{\alpha}_{B}, \alpha_{B B^{*}}\right)$ continues to shrink with higher trade costs, but since there is no longer a margin of adjustment through $\bar{\alpha}_{B^{*}}$, total acquisition demand also falls with higher trade costs.

Finally, in the right-most region of Figure 3, "Foreign", domestic acquisitions no longer occur, since whenever they are profitable relative to the acquisition price, foreign acquisitions are more profitable. Given the parameters of the simulation, the response of the acquisition market to trade costs is fairly tepid within this region. In moment, I will illustrate a few other cases in which the acquisition market is more responsive when only foreign acquisitions occur, where in particular, acquisition activity is increasing in trade costs.

\subsection{Trade liberalization and Aggregate Productivity}

In previous models of trade and firm heterogeneity, the predominant form of selection and productivity improvement is increased competition, and the evolutionary effect of getting rid of producers 
which can no longer profitably produce. Indeed, when trade costs fall in these models, competition toughens with increased import competition, and low productivity firms exit. In my model, this channel of selection is entirely closed, as all firms can profitably produce if they so choose. However, relatively unproductive firms may have an incentive to sell their assets to firms which are better able to utilize those assets. Critically, falling trade costs will affect foreign and domestic acquisition demand in opposite directions. In equilibrium, I will show that these competing effects, in the presence of the unique sorting of firms summarized in section two, result in a rich and decidedly non-monotonic relationship between trade costs and aggregate productivity.

To evaluate the effects of exogenous parameters, I first define the following measure of aggregate productivity, $\widetilde{\alpha}$ :

$$
\widetilde{\alpha}=s_{N A} \widetilde{\alpha}_{N A}+s_{A} \widetilde{\alpha}_{A}
$$

Here, $\widetilde{\alpha}_{N A}$ is the average productivity applied to units of capital which do not change ownership in the acquisition market, and $\widetilde{\alpha}_{A}$ is the average productivity applied to capital which changes ownership (acquired) in the acquisition market. Further, $s_{N A}$ and $s_{A}$ represent the respective shares of each group. Thus, $\widetilde{\alpha}$ will represent average productivity of firms operating in the product market, weighted by capital holdings. ${ }^{18}$ In terms of model parameters, $\widetilde{\alpha}$ is written as, ${ }^{19}$

$$
\widetilde{\alpha}=\int_{\alpha_{S}}^{\infty} \alpha g(\alpha) d \alpha+\int_{\alpha \in \Theta_{B}} \alpha g(\alpha) d \alpha+\int_{\alpha \in \Theta_{B^{*}}} \alpha g(\alpha) d \alpha
$$

Figure 4 illustrates the effects of trade costs on capital-weighted average productivity, where I have presented the results from four different simulations. The dark black line represents the same simulation as is used in Figure 3, with the corresponding cases noted at the top of the Figure. The dotted-dashed line represents an alternate simulation in which foreign investment costs are negligible, and thus, only foreign acquisitions occur for all values of $t$ greater than zero. The dashed line represents a different alternate simulation when foreign investment costs are prohibitive and only domestic acquisitions occur. Finally, the dotted (horizontal) line represents the simulation for which there is no acquisition market. For this "benchmark" simulation, trade costs do not affect aggregate productivity since all firms can profitably produce. Thus, the traditional method by

\footnotetext{
${ }^{18}$ It can be shown that this measure is equivalent to average sales per worker. See Spearot (2012) for a derivation.

${ }^{19}$ The naive function is written as

$$
\begin{aligned}
\widetilde{\alpha}= & \frac{1-\operatorname{Pr}\left(\alpha \in \Theta_{S}\right)}{1-\operatorname{Pr}\left(\alpha \in \Theta_{S}\right)+\operatorname{Pr}\left(\alpha \in \Theta_{B}\right)+\operatorname{Pr}\left(\alpha \in \Theta_{B^{*}}\right)} \cdot \frac{1}{1-\operatorname{Pr}\left(\alpha \in \Theta_{S}\right)} \int_{\alpha_{S}}^{\infty} \alpha g(\alpha) d \alpha \\
& +\frac{\operatorname{Pr}\left(\alpha \in \Theta_{B}\right)}{1-\operatorname{Pr}\left(\alpha \in \Theta_{S}\right)+\operatorname{Pr}\left(\alpha \in \Theta_{B}\right)+\operatorname{Pr}\left(\alpha \in \Theta_{B^{*}}\right)} \cdot \frac{1}{\operatorname{Pr}\left(\alpha \in \Theta_{B}\right)} \int_{\alpha \in \Theta_{B}} \alpha g(\alpha) d \alpha \\
& +\frac{\operatorname{Pr}\left(\alpha \in \Theta_{B^{*}}\right)}{1-\operatorname{Pr}\left(\alpha \in \Theta_{S}\right)+\operatorname{Pr}\left(\alpha \in \Theta_{B}\right)+\operatorname{Pr}\left(\alpha \in \Theta_{B^{*}}\right)} \cdot \frac{1}{\operatorname{Pr}\left(\alpha \in \Theta_{B^{*}}\right)} \int_{\alpha \in \Theta_{B^{*}}} \alpha g(\alpha) d \alpha
\end{aligned}
$$

Via the acquisition market clearing condition, $1-\operatorname{Pr}\left(\alpha \in \Theta_{S}\right)+\operatorname{Pr}\left(\alpha \in \Theta_{B}\right)+\operatorname{Pr}\left(\alpha \in \Theta_{B^{*}}\right)=1$, and $\widetilde{\alpha}$ is simplified as in $(25)$
} 
Figure 4: Trade Costs, Aggregate Productivity, and Acquisition Activity

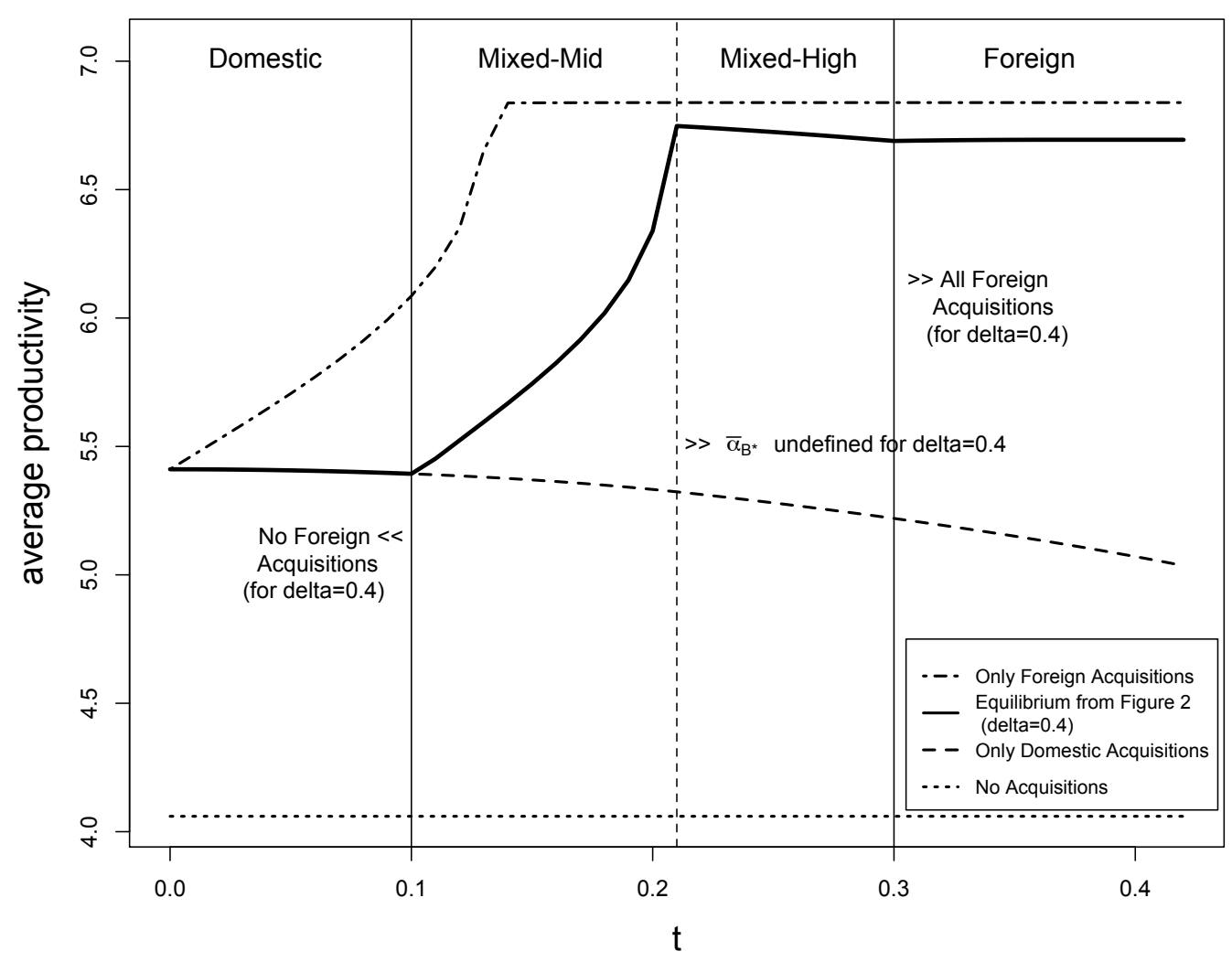

which firms select in and out of the market (as in Melitz and Ottaviano) is shut down, and hence, aggregate productivity is invariant to trade costs.

A number of striking features are evident in Figure 4. Most notably, higher trade costs can actually increase aggregate productivity. Consider first the dotted-dashed line for which $\delta$ is negligible and only foreign acquisitions occur for all positive values of $t$. This is the dotted-dashed line in Figure 4. Here, when trade costs rise, more firms find it profitable to buy the capital of an inefficient firm in the foreign market. This pushes up the acquisition price, and causes more inefficient firms to exit. Thus, when only foreign acquisitions occur, aggregate productivity improves with higher trade costs. In contrast, consider the dashed line in Figure 4 which is the simulation where $\delta$ is prohibitively high and only domestic acquisitions occur. Here, when trade costs rise, aggregate productivity falls uniformly. The intuition for this case is straightforward. Higher trade costs decrease the effective size of the world market for domestically oriented (all) firms. This reduces domestic acquisition demand, and hence, pushes down the price for assets in each market. Fewer low productivity firms sell, and aggregate productivity falls. Overall, in both cases, efficiency 
is maximized when reallocation is maximized, though the role of trade costs in this goal changes depending on the involvement of foreign acquisitions. Indeed, when foreign acquisitions dominate, tariffs should be set at a high level to maximized foreign demand. ${ }^{20}$ If instead foreign acquisitions are prohibitively costly, then tariffs should be set low to maximize domestic acquisition demand. This dichotomy provides a novel motivation for tariff setting that is different from the traditional market access motive. Indeed, the results indicate that a revenue neutral policy of raising tariffs to subsidize $\delta$ may be sufficient to maximize efficiency.

To examine the role of foreign acquisitions in an equilibrium with both domestic and foreign acquisitions, consider the dark black line in Figure 4, which plots aggregate productivity as a function of trade costs for the same parameters as in Figure 3. For this simulation, depending on the value of trade costs, the foreign share of the acquisition market may be zero, one, or between zero and one. In the left-most region of Figure 4, "Domestic", no foreign acquisitions occur, and higher trade costs decrease aggregate productivity as described above. However, this productivity result changes when increasing trade costs to the point of initial foreign acquisition penetration, which is "Mixed-Mid" in Figures 3 and 4. Analytically, the effects of trade costs for this case are ambiguous. This can been seen by deriving $\frac{\partial \widetilde{\alpha}}{\partial t}$ for "Mixed-Mid" :

$$
\frac{\partial \widetilde{\alpha}}{\partial t}=\frac{\partial \bar{\alpha}_{B^{*}}}{\partial t} g\left(\bar{\alpha}_{B^{*}}\right) \underbrace{\left(\bar{\alpha}_{B^{*}}-\alpha_{S}\right)}_{+}-\frac{\partial \underline{\alpha}_{B}}{\partial t} g\left(\underline{\alpha}_{B}\right) \underbrace{\left(\underline{\alpha}_{B}-\alpha_{S}\right)}_{+} \gtrless 0
$$

In (26), there are two competing effects of trade costs on aggregate productivity through the acquisition market. On one hand, higher trade costs make domestic acquisitions less profitable, and hence, this tends to reduce aggregate productivity via the second term in (26). On the other hand, trade costs make foreign acquisitions more profitable, and since there exists a margin through which firms can substitute between foreign acquisitions and no acquisitions $\left(\bar{\alpha}_{B^{*}}\right)$, higher trade costs increase aggregate productivity through the first term in (26). To ascertain which effect is larger, rearranging (26), we find that productivity improves with higher trade costs if:

$$
\underbrace{\frac{\frac{\partial \bar{\alpha}_{B^{*}}}{\partial t} g\left(\bar{\alpha}_{B^{*}}\right)}{\frac{\partial \underline{\alpha}_{B}}{\partial t}} \frac{\left(\bar{\alpha}_{B^{*}}-\alpha_{S}\right)}{g\left(\underline{\alpha}_{B}\right)}}_{\gtrless 1} \cdot \underbrace{\frac{\left(\underline{\alpha}_{B}-\alpha_{S}\right)}{(1}}_{>1}>1
$$

Here, $\frac{\left(\bar{\alpha}_{B^{*}}-\alpha_{S}\right)}{\left(\underline{\alpha}_{B}-\alpha_{S}\right)}>1$, since foreign acquiring firms are always more productive than domestic acquiring firms (Lemma 5). The question is whether $\frac{\frac{\partial \bar{\alpha}_{B^{*}}}{\partial t} \frac{g\left(\bar{\alpha}_{B^{*}}\right)}{\frac{\partial \underline{\alpha}_{B}}{\partial t}}}{g\left(\underline{\alpha}_{B}\right)}>1$. Depending on the mass of

\footnotetext{
${ }^{20}$ This can also be justified on welfare grounds where higher tariffs increase consumer surplus through increased aggregate efficiency. However, the effect is more modest given that higher acquisition demand reduces the number of varieties available, which tends to reduce welfare. Indeed, for the dotted-dashed line in the Figure 4, the number of active firms falls by $20 \%$, though consumer surplus is still maximized with higher tariffs via increased efficiency.
} 
firms around the $\underline{\alpha}_{B}$ and $\bar{\alpha}_{B^{*}}$, this may or may not be true. ${ }^{21}$ However, in Figure 4, parameters are such that aggregate productivity improves sharply with higher trade costs. As discussed above, despite a positive measure of domestic acquiring firms, there exists a margin through which firms can substitute between foreign acquisitions, $B^{*}$, and no acquisitions $N$. This opens the door for the novel prediction that higher trade costs improve aggregate productivity through the acquisition market.

To further highlight the role of foreign acquisitions through the equilibrium sorting of firms, consider "Mixed-High". For this case, there exists a continuous region of productivity such that both domestic and foreign acquisitions occur, but trade costs are high enough such that $\bar{\alpha}_{B^{*}}$ is not defined. Of note, this case is observationally equivalent to a comparable model based on CES demand for any parameter values such that domestic and foreign acquisitions occur simultaneously. As illustrated in Figure 4, trade costs decrease aggregate productivity within this region. Analytically, this can be seen by deriving $\frac{\partial \widetilde{\alpha}}{\partial t}$ for this case:

$$
\frac{\partial \widetilde{\alpha}}{\partial t}=-\frac{\partial \underline{\alpha}_{B}}{\partial t} g\left(\underline{\alpha}_{B}\right) \underbrace{\left(\underline{\alpha}_{B}-\alpha_{S}\right)}_{+}<0
$$

In (28), higher trade costs decrease aggregate productivity. Despite both domestic and foreign acquisitions occurring, there is no substitution between $B^{*}$ and $N$ as in "Mixed-Mid" , and hence, changes to foreign acquisitions have no effect on total acquisition demand. Overall, aggregate productivity falls. The key is that once trade costs are large enough such that $\bar{\alpha}_{B^{*}}$ is no longer defined, foreign acquisitions can no longer affect total acquisition demand as in "Mixed-Mid" .

Finally, in "Foreign", trade costs are large enough such that domestic acquisitions never occur, and the only substitution in and out of the acquisition market is between $B^{*}$ and $N$. Here the response of the acquisition market is fairly tepid. However, when there is a response, higher trade costs make foreign acquisitions profitable for a larger set of firms, more productivity enhancing acquisitions occur, and aggregate productivity improves.

Overall, the simulations in Figure 4 detail a diverse response of aggregate productivity and acquisition behavior to trade costs. The novel contribution of this section is showing how substitution in and out of the acquisition market, especially by foreign acquiring firms, affects aggregate productivity. Indeed, the unique sorting of firms delivered by the equilibrium acquisition model opens the door for a rich and complex relationship between trade costs and aggregate productivity through these margins of substitution, where the possibility that reciprocal trade liberalization reduces aggregate productivity motivates a new question in terms of evaluating the impact of trade barriers on productivity. In particular, the paper motivates an interaction between the effects of tariffs or

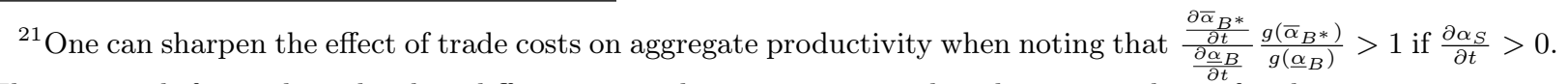
This a straightforward result when differentiating the acquisition market clearing condition for this case.
} 
other trade barriers and the composition of investment demand when evaluating productivity. If foreign acquisition demand is significant and particularly footloose with respect to trade costs, then the productivity enhancing effect of tariffs cuts will be mitigated or potentially overturned. While this relationship is unlikely to add much insight when evaluating the relationships between close trading partners between which there are few foreign acquisitions (for example the Canada-US FTA as in Trefler (2004) and Breinlich (2008)), the explosive growth of foreign acquisitions between many other trading partners begs the question whether future tariff cuts and trade agreements may alter efficiency through this channel. Further, the mere presence of foreign acquisitions may alter the incentives for governments to levy tariffs, especially when issues of efficiency are more pronounced.

\section{Conclusion}

In this paper, I presented an industry-equilibrium model of acquisition behavior in which firms trade capital after productivity has been realized. I make two main points. First, I show that using a common variable-elasticity (linear) demand system, firms that benefit from acquisitions for market access are not the same firms that benefit from acquisitions for cost reduction. Hence, the relative size of trade costs determine the qualitative sorting of firms into acquisition choices. Second, I identify a role of foreign acquisitions in tempering, and in some cases reversing, the beneficial effects of trade liberalization. Specifically, if there exists an active substitution between foreign acquisitions and no acquisitions, aggregate productivity may fall with trade liberalization.

Overall, this paper adds a number of empirical questions onto the ever growing list of issues to evaluate with firm-level data. The basic prediction that mid productivity firms are more likely to acquire is confirmed in a companion paper, Spearot (2012), using the Compustat database. However, while a number of authors have established a positive effect of foreign acquisitions vis-a-vis domestic acquisitions on firm-level performance (Arnt and Anselm, 2008; Arnold and SarzynskaJavorcik, 2009), the predictions of the model, and in particular the novel relationship between trade liberalization and aggregate productivity via reallocation in the acquisition market, have yet to be tested. This is an issue I plan to take up in future empirical work. 


\section{References}

[1] Ardnt, Christian and Mattes Anselm (2008), "Impact of Inward FDI and Foreign Ownership on the Performance of German Multinational Firms", mimeo Institute for Applied Economic Research.

[2] Arnold, Jens and Beata Sarzynska-Javorcik (2009), Gifted Kids or Pushy Parents? Foreign Acquisitions and Plant Performance in Indonesia. CEPR Discussion Paper 5065, Centre for Economic Policy Research.

[3] Brainard, S. Lael (1997), "An Empirical Assessment of the Proximity - Concentration Trade-off Between Multinational Sales and Trade," American Economic Review, vol. 87, pp. 520-544.

[4] Breinlich, Holger (2008), "Trade Liberalization and Industrial Restructuring through Mergers and Acquisitions," Journal of International Economics, Vol. 76.

[5] Bustos, Paula (2011), "Trade Liberalization, Exports and Technology Upgrading: Evidence on the impact of MERCOSUR on Argentinian Firms", American Economic Review, Vol. 101-1, pp. 304-340.

[6] Campbell, J., and H. Hopenhayn (2005): "Market Size Matters," Journal of industrial economics, Vol. 53-1, pp. 1-25.

[7] Chisik, Richard, and Ronald Davies (2004), "Gradualism in Tax Treaties with Irreversible Foreign Direct Investment", International Economic Review, Vol. 45, pp. 113-139.

[8] Chor, Davin (2008), "Subsidies for FDI: Implications from a Model with Heterogeneous Firms", Journal of International Economics, Vol. 78, pp. 113-125.

[9] Denececkre, Ray and Carl Davidson (1985), "Incentives to Form Coalitions with Bertrand Competition", Rand Journal of Economics, vol. 16-4 pp. 473-486.

[10] Doms, Mark, and Timothy Dunne (1998), "Capital Adjustment Patterns in Manufacturing Plants", Review of Economic Dynamics, vol 1, pp. 409-429.

[11] J. Ederington, Josh, and Phillip McCalman (2009), "International Trade and Industrial Dynamics", International Economic Review, Vol. 50: pp. 961-989.

[12] Farrell, Joseph and Carl Shapiro (1990), "Horizontal Mergers: An Equilibrium Analysis", American Economic Review, vol. 80-1, pp. 107-126.

[13] Feenstra, Robert and D. Weinstein (2010), "Globalization, Markups, and the US Price Level," Discussion paper, National Bureau of Economic Research. 
[14] Foster, L., J. Haltiwanger, and C. Syverson (2008), "Reallocation, Firm Turnover, and Efficiency: Selection on Productivity or Profitability?" The American Economic Review, pp. 394-425.

[15] Glass, Amy and Kamal Saggi (2010), "Coordinating FDI Policies Among Host Countries", mimeo Texas A\&M University.

[16] Hayashi, Fumio (1982), "Tobin's Marginal q and Average q: A neoclassical Interpretation", Econometrica, vol. 50, pp. 213-223

[17] Head, Keith and John Reis (2003), "Heterogeneity and the FDI versus Export Decision of Japanese Manufacturers", Journal of Japanese and International Economies, vol. 17-4, pp. 448-467.

[18] Helpman, Elhanan, Marc Melitz and Stephen Yeaple (2004), "Exports versus FDI with heterogeneous firms." American Economic Review, vol 94, 300-316.

[19] Jovanovic, Boyan and Peter Rousseau (2002), "The Q-Theory of Mergers, " American Economic Review, vol. 92, pp. 198-204.

[20] Navaretti, Giorgio Barba and Anthony Venables, Multinational Firms in the World Economy, Princeton University Press, 2006.

[21] Melitz, Marc (2003), "The Impact of Trade on Intra-Industry Reallocations and Aggregate Industry Productivity", Econometrica, Vol. 71, pp. 1695-1725.

[22] Melitz, Marc and Gianmarco I.P. Ottaviano (2008), "Market Size, Trade, and Productivity", Review of Economic Studies, Vol. 75-1, pp. 295-316.

[23] Nocke, Volker and Stephen Yeaple (2006), "Globalization and Endogenous Firm Scope", mimeo University of Pennsylvania.

[24] Nocke, Volker and Stephen Yeaple (2007), "Cross-Border Mergers and Acquisitions versus Greenfield Foreign Direct Investment: The Role of Firm Heterogeneity", Journal of International Economics, 2007, vol. 72-2, pp. 336-365.

[25] Perry, Martin and Robert Porter (1985), "Oligopoly and the Incentive for Horizontal Merger", American Economic Review, vol. 75, pp. 219-227.

[26] OECD, New Patterns in Industrial Globalisation - Cross-Border Mergers and Acquisitions and Strategic Alliances, Organization for Economic Cooperation and Development, 2001

[27] Rauch, James E. (1999), "Networks versus markets in international trade", Journal of International Economics, vol. 48, pp. 7-35. 
[28] Salant, Stephen W., Sheldon Switzer and Robert J. Reynolds (1983), "Losses from Horizontal Merger: The Effects of an Exogenous Change in Industry Structure on Cournot-Nash Equilibrium", The Quarterly Journal of Economics, vol. 98, pp. 185-199.

[29] Spearot, Alan (2012), "Firm Heterogeneity, New Investment, and Acquisitions", Journal of Industrial Economics, March.

[30] Trefler, D. (2004): "The Long and Short of the Canada-US Free Trade Agreement," American Economic Review, pp. 870-895.

[31] United nations conference on trade and development, World investment report 2000 : Crossborder Mergers and Acquisitions and Development, The United Nations, 2000. 


\section{A Proofs}

\section{Lemma 1}

To begin the derivation of Lemma 1, I will focus on $\alpha \leq \frac{t}{4 b k(A-t)}$. Differentiating $\frac{A^{2} \alpha k}{2(4 \alpha k b+1)(2 \alpha k b+1)}$ with respect to $\alpha$ yields:

$$
\frac{\partial \Delta \Pi(\alpha)}{\partial \alpha}=\frac{A \alpha k\left(1-8 b^{2} \alpha^{2} k^{2}\right)}{2(4 \alpha k b+1)^{2}(2 \alpha k b+1)^{2}}
$$

The positive root of $\Delta \Pi(\alpha)$ is $\alpha=\frac{\sqrt{2}}{4 b k}$. However, this maximum is irrelevant if $\frac{t}{4 b k(A-t)}<\frac{\sqrt{2}}{4 b k}$. This condition simplifies to $\frac{\sqrt{2}}{4 b k}\left(\frac{2 A-(2+\sqrt{2}) t}{A-t}\right)>0$. This is satisfied if $t<\frac{2}{2+\sqrt{2}} A$. Thus, if $t<\frac{2}{2+\sqrt{2}} A$, $\frac{\partial \Delta \Pi(\alpha)}{\partial \alpha}>0$ for $\alpha \leq \frac{t}{4 b k(A-t)}$. If $t>\frac{2}{2+\sqrt{2}} A, \frac{\partial \Delta \Pi(\alpha)}{\partial \alpha}>0$ for $\alpha \in\left(0, \frac{\sqrt{2}}{4 b k}\right)$ and $\frac{\partial \Delta \Pi(\alpha)}{\partial \alpha}>0$ for $\alpha \in\left(\frac{\sqrt{2}}{4 b k}, \frac{t}{4 b k(A-t)}\right)$

Now turning to $\alpha \in\left(\frac{t}{4 b k(A-t)}, \frac{t}{2 b k(A-t)}\right)$, over this range, $\Delta \Pi(\alpha)$ has two roots (in $\left.\alpha\right)$. They are written as:

$$
\begin{aligned}
\alpha_{1} & =\frac{\sqrt{2}(-2 A+(2+\sqrt{2}) t)}{4 b k(-A+(A-t)(\sqrt{2}+1))} \\
\alpha_{2} & =-\frac{\sqrt{2}(2(A-t)+\sqrt{2} t)}{4 b k(A+(A-t)(\sqrt{2}-1))}<0
\end{aligned}
$$

Clearly, $\alpha_{2}$ is not relevant. The root $\alpha_{1}$ is relevant if the following condition holds.

$$
\alpha_{1}-\frac{t}{4 b k(A-t)}=\frac{\sqrt{2}(2 A-t) \overbrace{((2+\sqrt{2}) t-2 A)}^{(-) \text {if } t<\frac{2}{2+\sqrt{2}} A}}{8 b k(A-t) \underbrace{(-A+(A-t)(\sqrt{2}+1))}_{(+) \text {if } t<\frac{2}{2+\sqrt{2}} A(\text { see below })}}<0
$$

To see that $-A+(A-t)(\sqrt{2}+1)>0$ if $t<\frac{2}{2+\sqrt{2}} A$, rearrange the first expression to read $t<\left(\frac{\sqrt{2}}{1+\sqrt{2}}\right) A$. Multiplying the top and bottom by $\sqrt{2}$, we get $t<\frac{2}{2+\sqrt{2}} A$. Thus, since the numerator and denominator always have the opposite sign, it must always be the case that $\alpha_{1}<\frac{t}{4 b k(A-t)}$, and thus not relevant in the mid range of productivity.

Both $\alpha_{1}<\frac{t}{4 b k(A-t)}$ and $\alpha_{2}<0$ imply that the roots of $\Delta \Pi(\alpha)$ do not occur over the range $\frac{t}{4 b k(A-t)}<\alpha \leq \frac{t}{2 b k(A-t)}$. Thus, the sign of $\frac{\partial \Delta \Pi(\alpha)}{\partial \alpha}$ is constant over this range. To see when $\frac{\partial \Delta \Pi(\alpha)}{\partial \alpha}>0$, note that:

$$
\frac{\partial \Delta \Pi\left(\frac{t}{4 b k(A-t)}\right)}{\partial \alpha}=\frac{k(A-t)^{2} \overbrace{\left(2 A^{2}-4 A t+t^{2}\right)}^{(+) \text {if } t<\frac{2}{2+\sqrt{2}} A}}{2(2 A-t)^{2}}
$$


Clearly, the sign of $\frac{\partial \Delta \Pi(\alpha)}{\partial \alpha}$ over the mid range of productivity is dependent on the size of trade costs relative to the market, and is positive if $t<\frac{2}{2+\sqrt{2}} A$. Hence, for $t<\frac{2}{2+\sqrt{2}} A, \frac{\partial \Delta \Pi(\alpha)}{\partial \alpha}>0$ for $\alpha \in\left(\frac{t}{4 b k(A-t)}, \frac{t}{2 b k(A-t)}\right)$. Else, if $t>\frac{2}{2+\sqrt{2}} A, \frac{\partial \Delta \Pi(\alpha)}{\partial \alpha}<0$ for $\alpha \in\left(\frac{t}{4 b k(A-t)}, \frac{t}{2 b k(A-t)}\right)$.

Finally, for $\alpha \in\left(\frac{t}{2 b k(A-t)}, \infty\right)$, I can write:

$$
\frac{\partial \Delta \Pi(\alpha)}{\partial \alpha}=\frac{k(2 A-t)\left(4-8 b^{2} \alpha^{2} k^{2}\right)}{2(4 \alpha k b+2)^{2}(2 \alpha k b+2)^{2}}
$$

The positive solution to $\frac{\partial \Delta \Pi(\alpha)}{\partial \alpha}=0$ is $\frac{\sqrt{2}}{2 b k}$. It is also clear that for $\alpha<\frac{\sqrt{2}}{2 b k}$, $\frac{\partial \Delta \Pi(\alpha)}{\partial \alpha}>0$, and for $\alpha>\frac{\sqrt{2}}{2 b k}, \frac{\partial \Delta \Pi(\alpha)}{\partial \alpha}<0$. Again, this root is only relevant when $\frac{t}{2 b k(A-t)}<\frac{\sqrt{2}}{2 b k}$. This occurs if $t<\frac{2}{2+\sqrt{2}} A$.

Overall, I have shown that if $t<\frac{2}{2+\sqrt{2}} A, \frac{\partial \Delta \Pi(\alpha)}{\partial \alpha}>0$ for $\alpha \in\left(0, \frac{\sqrt{2}}{2 b k}\right)$, and $\frac{\partial \Delta \Pi(\alpha)}{\partial \alpha}<0$ for $\alpha \in\left(\frac{\sqrt{2}}{2 b k}, \infty\right)$. In contrast, if $t>\frac{2}{2+\sqrt{2}} A, \frac{\partial \Delta \Pi(\alpha)}{\partial \alpha}>0$ for $\alpha \in\left(0, \frac{\sqrt{2}}{4 b k}\right)$, and $\frac{\partial \Delta \Pi(\alpha)}{\partial \alpha}<0$ for $\alpha \in\left(\frac{\sqrt{2}}{4 b k}, \infty\right)$

\section{Lemma 2}

Clearly, $\Delta \Pi^{*}(0)=-\delta$. In addition, it is straightforward to show that $\lim _{\alpha \rightarrow \infty} \Delta \Pi^{*}(\alpha)=\frac{(2 A-t) t}{4 b}-\delta$. To derive the slope properties of $\Delta \Pi^{*}(\alpha)$, note that for $\alpha \leq \frac{t}{2 b k(A-t)}, \frac{A^{2} \alpha k}{2(2 b \alpha k+1)}$ is equal to the no acquisition profit function, $\pi^{N}(\alpha)$. Thus, for $\alpha \leq \frac{t}{2 b k(A-t)}, \frac{\partial \Delta \Pi^{*}(\alpha)}{\partial \alpha}>0$. For $\alpha>\frac{t}{2 b k(A-t)}$, with some work, one can show that the only positive root of $\Delta \Pi^{*}(\alpha)$ is $\widehat{\alpha}=\frac{\sqrt{2}(2 A+t+\sqrt{2} t)}{2 b k(2 A-2 t-\sqrt{2} t)}$. To start, differentiate $\Delta \Pi^{*}(\alpha)$ with respect to $\alpha$, set equal to zero, and solve for $\alpha$ :

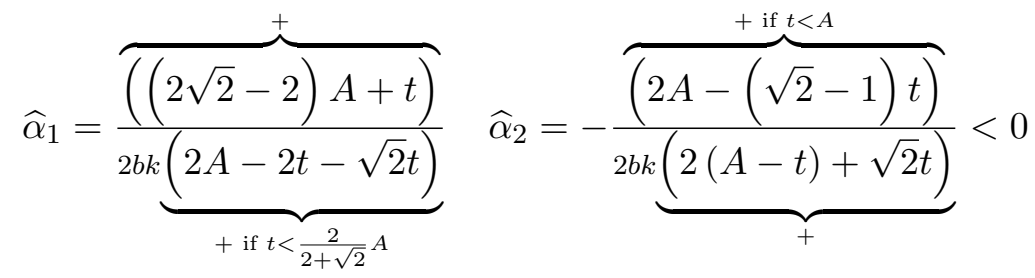

Clearly, $\widehat{\alpha}_{2}$ is irrelevant. Regarding $\widehat{\alpha}_{1}$, it is only relevant if $t<\frac{2}{2+\sqrt{2}} A$. To see this, note that $\widehat{\alpha}_{1}>\frac{t}{2 b k(A-t)}$ if the following holds:

$$
\widehat{\alpha}_{1}-\frac{t}{2 b k(A-t)}=\frac{(\sqrt{2}-1)(2 A-t) A}{2 b k(A-t)((2-\sqrt{2}) A-t)}>0
$$

This clearly holds if $t<(2-\sqrt{2}) A$. Note that $t<(2-\sqrt{2}) A$ can be written as $t<(2-\sqrt{2}) \frac{2+\sqrt{2}}{2+\sqrt{2}} A=$ $\frac{4-2+2 \sqrt{2}-2 \sqrt{2}}{2+\sqrt{2}} A=\frac{2}{2+\sqrt{2}} A$.

Now, all that is left is identifying the sign of $\frac{\partial \Delta \Pi^{*}(\alpha)}{\partial \alpha}$ on either side of $\widehat{\alpha}$. At $\alpha=\frac{t}{2 b k(A-t)}$, 
$\frac{\partial \Delta \Pi^{*}(\alpha)}{\partial \alpha}=\frac{k(A-t)^{2}}{2}>0 . \quad$ The second derivative at $\widehat{\alpha}_{1}$ gives us guidance to the shape at the peak. Precisely:

$$
\frac{\partial^{2} \Delta \Pi^{*}\left(\widehat{\alpha}_{1}\right)}{\partial \alpha^{2}}=-\frac{\overbrace{(17 \sqrt{2}-24)}^{+} b k^{2}(2 A-2 t-\sqrt{2} t)^{4}}{4(2 A-t) A}
$$

Clearly, $\frac{\partial^{2} \Delta \Pi^{*}\left(\widehat{\alpha}_{1}\right)}{\partial \alpha^{2}}<0$ only if $t<\frac{2}{2+\sqrt{2}} A$. Thus, if $t<\frac{2}{2+\sqrt{2}} A, \widehat{\alpha}_{1}$ is a maximum, and $\frac{\partial \Delta \Pi^{*}(\alpha)}{\partial \alpha}<0$ for $\alpha>\widehat{\alpha}_{1}$. As $t \rightarrow \frac{2}{2+\sqrt{2}} A, \widehat{\alpha}_{1} \rightarrow \infty$, where $\frac{\partial^{2} \Delta \Pi^{*}\left(\widehat{\alpha}_{1}\right)}{\partial \alpha^{2}} \rightarrow 0$.

\section{Proposition 1}

To prove Lemma 3, I need to establish that $\alpha_{S}<\underline{\alpha}_{B}<\bar{\alpha}_{B}$. Once this ranking is established, Lemma 1 is immediate via the preference conditions in (14) and (17). To show $\alpha_{S}<\underline{\alpha}_{B}$, first note that from (13) and (15) it must be the case that:

$$
\pi^{B}\left(\underline{\alpha}_{B}\right)-\pi^{N}\left(\underline{\alpha}_{B}\right)=\pi^{N}\left(\alpha_{S}\right)
$$

Rearranging,

$$
\frac{1}{2} \pi^{B}\left(\underline{\alpha}_{B}\right)-\pi^{N}\left(\underline{\alpha}_{B}\right)=\pi^{N}\left(\alpha_{S}\right)-\frac{1}{2} \pi^{B}\left(\underline{\alpha}_{B}\right)
$$

Since $\frac{1}{2} \pi^{B}\left(\underline{\alpha}_{B}\right)<\pi^{N}\left(\underline{\alpha}_{B}\right)$, the RHS must also be negative in equilibrium. This is only possible if $\alpha_{S}<\underline{\alpha}_{B}$. By definition, $\underline{\alpha}_{B}<\bar{\alpha}_{B}$.

\section{Proposition 2}

To show that $\alpha_{S}<\underline{\alpha}_{B}^{*}<\bar{\alpha}_{B}^{*}$, the analysis is similar. Equilibrium conditions dictate that:

$$
\pi^{B^{*}}\left(\underline{\alpha}_{B}^{*}\right)-\pi^{N}\left(\underline{\alpha}_{B}^{*}\right)-\delta=\pi^{N}\left(\alpha_{S}\right)
$$

Subtracting $\frac{1}{2} \pi^{B^{*}}\left(\underline{\alpha}_{B}^{*}\right)$, we get:

$$
\frac{1}{2} \pi^{B^{*}}\left(\underline{\alpha}_{B}^{*}\right)-\pi^{N}\left(\underline{\alpha}_{B}^{*}\right)-\delta=\pi^{N}\left(\alpha_{S}\right)-\frac{1}{2} \pi^{B^{*}}\left(\underline{\alpha}_{B}^{*}\right)
$$

Since $\frac{1}{2} \pi^{B^{*}}\left(\underline{\alpha}_{B}^{*}\right) \leq \pi^{N}\left(\underline{\alpha}_{B}^{*}\right)$, the LHS of the above condition must be negative. Hence, the RHS, $\pi^{N}\left(\alpha_{S}\right)-\frac{1}{2} \pi^{B^{*}}\left(\underline{\alpha}_{B}^{*}\right)$ must also be negative. This can only be the case if $\underline{\alpha}_{B}^{*}>\alpha_{S}$. Finally, $\bar{\alpha}_{B}^{*}>\underline{\alpha}_{B}^{*}$ follows from the shape of $\Delta \Pi^{*}(\alpha)$ and the definitions of $\underline{\alpha}_{B}^{*}$ and $\bar{\alpha}_{B}^{*}$. Thus, $\alpha_{S}<\underline{\alpha}_{B}^{*}<\bar{\alpha}_{B}^{*}$ when both $\underline{\alpha}_{B}^{*}$ and $\bar{\alpha}_{B}^{*}$ are defined, and using the indifference conditions in (14) and (20), we have the result in Lemma 4. When $\bar{\alpha}_{B}^{*}$ is not defined, the results in Lemma 4 follow given that $\Delta \Pi^{*}(\alpha)<R_{a}$ for $\alpha<\underline{\alpha}_{B}^{*}$, and $\Delta \Pi^{*}(\alpha)>R_{a}$ for $\alpha>\underline{\alpha}_{B}^{*}$.

\section{Proposition 3}

To start, note that from Lemma 2, if $\frac{(2 A-t) t}{4 b}>\delta, \lim _{\alpha \rightarrow \infty} \Delta \Pi^{*}(\alpha)>0$. Since by Lemma $2 \Delta \Pi(0)=$ $\lim _{\alpha \rightarrow \infty} \Delta \Pi(\alpha)=0$, and $\Delta \Pi^{*}(0)=-\delta$, this guarantees that $\Delta \Pi^{*}(\alpha)$ and $\Delta \Pi(\alpha)$ cross at least once over the support of $\alpha$. To prove that $\Delta \Pi^{*}(\alpha)$ and $\Delta \Pi(\alpha)$ cross only once at a unique value of $\alpha$, 
I must show that $\frac{\Delta \Pi^{*}(\alpha, A)}{\partial \alpha}>\frac{\Delta \Pi(\alpha, A)}{\partial \alpha}$. To start, note that this condition simplifies to

$$
\frac{\partial \pi^{B^{*}}(\alpha)}{\partial \alpha}>\frac{\partial \pi^{B}(\alpha)}{\partial \alpha}
$$

Note that $\frac{\partial \pi^{B^{*}}(\alpha)}{\partial \alpha}$ is written as:

$$
\frac{\partial \pi^{B^{*}}(\alpha)}{\partial \alpha}=\frac{A^{2} k}{(2 b \alpha k+1)^{2}}
$$

and $\frac{\partial \pi^{B}(\alpha)}{\partial \alpha}$ is written as:

$$
\frac{\partial \pi^{B}(\alpha)}{\partial \alpha}=\left\{\begin{array}{ll}
\frac{A^{2} k}{(4 b \alpha k+1)^{2}} & \alpha \leq \frac{t}{4 b k(A-t)} \\
\frac{A^{2} k}{(2 b \alpha k+1)^{2}}-\frac{t k(4 A-t)}{4(2 b \alpha k+1)^{2}} & \alpha>\frac{t}{4 b k(A-t)}
\end{array}\right\}
$$

Clearly, $\frac{\partial \pi^{B^{*}}(\alpha)}{\partial \alpha}>\frac{\partial \pi^{B}(\alpha)}{\partial \alpha}$ for all $\alpha$. Hence, when $\frac{(2 A-t) t}{4 b}>\delta, B^{*} \succ B$ if $\alpha>\alpha_{B B^{*}}$. If $\frac{(2 A-t) t}{4 b}<\delta$, $B \succ B^{*}$ for all $\alpha$.

\section{Existence and Uniqueness of $R_{a}$}

The supply of selling firms, starting from 0 at $R_{a}=0$, is increasing in the acquisition price. In contrast, starting from positive demand at $R_{a}=0$, the demand for capital is decreasing in the acquisition price. Eventually, there exists a value of $R_{a}$ at which acquisition demand, both foreign and domestic, is zero. Hence, there exists a unique $R_{a}>0$ such that (23) is satisfied.

\section{Existence and Uniqueness of $A$}

A sketch of the proof is as follows. A full proof is available at the author's website. Through (24), there are direct effects of $A$ on the profit function, all of which are positive. There are also indirect effects through the limits of integration. However, by applying Leibniz rule, all indirect effects cancel out, since the productivity cutoffs are defined by the equality of profit functions, which are of course the intergrands in (24). Thus, regardless which acquisition equilibrium the industry is in, all indirect effects are zero, and the derivative of the left-hand side of (24) is always positive. Since profits are zero when $A=0$, provided that the fixed entry costs are not too high, there exists a unique equilibrium value of $A$. 


\section{Possible Equilibria}

\begin{tabular}{lllll}
\hline \hline Case & Sorting of Firms (in $\alpha)$ & $\Theta_{N}$ & $\Theta_{B}$ & $\Theta_{B *}$ \\
\hline Discussed in Section 3 & & & \\
$\mathbf{1}$ & $S, N, B, N$ & $\left(\alpha_{S}, \underline{\alpha}_{B}\right) \cup\left(\bar{\alpha}_{B}, \infty\right)$ & $\left(\underline{\alpha}_{B}, \bar{\alpha}_{B}\right)$ & $\emptyset$ \\
$\mathbf{2}$ & $S, N, B, B^{*}, N$ & $\left(\alpha_{S}, \underline{\alpha}_{B}\right) \cup\left(\bar{\alpha}_{B^{*}}, \infty\right)$ & $\left(\underline{\alpha}_{B}, \alpha_{B B^{*}}\right)$ & $\left(\alpha_{B B^{*}}, \bar{\alpha}_{B^{*}}\right)$ \\
$\mathbf{3}$ & $S, N, B, B^{*}$ & $\left(\alpha_{S}, \underline{\alpha}_{B}\right)$ & $\left(\underline{\alpha}_{B}, \alpha_{B B^{*}}\right)$ & $\left(\alpha_{\left.B B^{*}, \infty\right)}\right)$ \\
$\mathbf{4}$ & $S, N, B^{*}$ & $\left(\alpha_{S}, \underline{\alpha}_{B}\right)$ & $\emptyset$ & $\left(\underline{\alpha}_{B^{*}}, \infty\right)$ \\
$\mathbf{5}$ & $S, N, B^{*}, N$ & $\left(\alpha_{S}, \underline{\alpha}_{B^{*}}\right) \cup\left(\bar{\alpha}_{B^{*}}, \infty\right)$ & $\emptyset$ & $\left(\underline{\alpha}_{B^{*}}, \bar{\alpha}_{B^{*}}\right)$ \\
Not discussed in Section 3 & & & \\
$\mathbf{6}$ & $S, N, B, N, B^{*}, N$ & $\left(\alpha_{S}, \underline{\alpha}_{B}\right) \cup\left(\bar{\alpha}_{B}, \underline{\alpha}_{B^{*}}\right) \cup\left(\bar{\alpha}_{B^{*}}, \infty\right)$ & $\left(\underline{\alpha}_{B}, \bar{\alpha}_{B}\right)$ & $\left(\underline{\alpha}_{B^{*}}, \bar{\alpha}_{B^{*}}\right)$ \\
$\mathbf{7}$ & $S, N, B, N, B^{*}$ & $\left(\alpha_{S}, \underline{\alpha}_{B}\right) \cup\left(\bar{\alpha}_{B}, \underline{\alpha}_{B^{*}}\right)$ & $\left(\underline{\alpha}_{B}, \bar{\alpha}_{B}\right)$ & $\left(\underline{\alpha}_{B^{*}}, \infty\right)$ \\
\hline
\end{tabular}

The five main cases are discussed at the end of Section 2 and the beginning of Section 3. The two additional cases are possible when the following conditions are true:

$$
\begin{aligned}
\frac{\partial \Delta \Pi\left(\alpha_{B B^{*}}\right)}{\partial \alpha} & <0<\frac{\partial \Delta \Pi^{*}\left(\alpha_{B B^{*}}\right)}{\partial \alpha} \\
\text { and } \Delta \Pi\left(\alpha_{B B^{*}}\right) & <R_{A}
\end{aligned}
$$

Essentially, for there to be a region in-between domestic and foreign acquisitions such that doing nothing is profitable, at the indifference point between domestic and foreign acquisitions, neither should be profitable relative to the acquisition price but foreign acquisition incentives should be increasing in productivity while domestic acquisition incentives should be decreasing in productivity.

\section{B Simulation Details}

\section{Parameters for Simulation of the model}

\begin{tabular}{lll}
\hline \hline Parameter & Value & Notes \\
\hline$\theta$ & 10 & Maximum marginal utility of the differentiated good \\
$\eta$ & 1 & Utility parameter \\
$\gamma$ & 0.1 & Utility parameter \\
$k$ & 1 & Initial capital endowment per firm \\
$F_{E}$ & 1 & Fixed cost of entry \\
$G(\alpha)$ & $1-\left(\frac{1}{\alpha}\right)^{h}$ & Pareto productivity distribution, $\alpha \in(1, \infty)$ \\
$h$ & 1.3 & Pareto dispersion parameter \\
$\delta$ & varies & Fixed cost of foreign investment \\
$t$ & varies & Per-unit cost of exports \\
\hline \hline
\end{tabular}

The simulation itself uses Broyden's method for solving the system of nonlinear equations. The difficulty in solving the model is that to use a standard Newton-Raphson method, one needs to solve for the explicit form of the Jacobian of the system of equations. Broyden's method approximates this Jacobian after each iteration.

As there is an analytical solution for the case of free trade, I start with this case and incrementally adjust $t$ and $\delta$ away from free trade, using the results from the previous case as the initial conditions of the simulation, and in particular, the initial guess of the Jacobian. The code of the simulation used to construct the figures in the paper is available upon request. 